Article

\title{
Knowledge Mapping of Optimal Taxation Studies: A Bibliometric Analysis and Network Visualization
}

\author{
Liliana Barbu ${ }^{1, *(\mathbb{C})}$, Diana Marieta Mihaiu ${ }^{1}$, Radu-Alexandru Șerban ${ }^{2}{ }^{(1)}$ and Alin Opreana ${ }^{2}(\mathbb{D})$ \\ 1 Department of Finance and Accounting, Faculty of Economic Sciences, Lucian Blaga University of Sibiu, \\ 550024 Sibiu, Romania; diana.mihaiu@ulbsibiu.ro \\ 2 Department of Management, Marketing and Business Administration, Faculty of Economic Sciences, Lucian \\ Blaga University of Sibiu, 550024 Sibiu, Romania; radu.serban@ulbsibiu.ro (R.-A.S,.); \\ alin.opreana@ulbsibiu.ro (A.O.) \\ * Correspondence: liliana.barbu@ulbsibiu.ro
}

check for updates

Citation: Barbu, L.; Mihaiu, D.M.;

Serban, R.-A.; Opreana, A. Knowledge Mapping of Optimal Taxation Studies: A Bibliometric Analysis and Network Visualization. Sustainability 2022, 14, 1043.

https://doi.org/10.3390/su14021043

Academic Editors:

Aleksander Aristovnik and

Francesco Tajani

Received: 6 November 2021

Accepted: 14 January 2022

Published: 17 January 2022

Publisher's Note: MDPI stays neutral with regard to jurisdictional claims in published maps and institutional affiliations.

Copyright: (C) 2022 by the authors. Licensee MDPI, Basel, Switzerland. This article is an open access article distributed under the terms and conditions of the Creative Commons Attribution (CC BY) license (https:// creativecommons.org/licenses/by/ $4.0 /)$.

\begin{abstract}
The problem of tax policy design has been an important concern over the years, involving comprehensive scientific research. In this study, our major goal was to examine and map the optimal taxation research thematic structure by using bibliometric analysis. The analysis was carried out with the CiteSpace software on publications indexed by Web of Science (WoS) between 1975 and 2021. This document offers an actual bibliometric analysis of the current research climate in terms of optimal taxation, based on the following aspects: (1) descriptive characteristics of publication outputs (distribution by years, authors, countries, journals); (2) collaboration analysis of authors, institutions, and countries; (3) co-citation analysis of cited journals, cited authors, and cited references; and (4) keywords' co-occurrence analysis. We constructed a knowledge map about optimal taxation research to provide a wide visual brief of the actual research in the domain of optimal tax policy. The current study adds knowledge by presenting the state of the art of the most significant studies published in the field of optimal taxation research.
\end{abstract}

Keywords: bibliometric analysis; optimal taxation; tax optimization; CiteSpace

\section{Introduction}

Both theoretically and empirically, taxation is an attractive topic for research since the real-life provocations related to tax collection are related to the analytical concerns of scientists. Taxes are a category of public incomes that vary from alternative modes of financing, including public debt, revenue from state pioneering activities, and income from taxpayers' payments for various administrative requests. Currently, the world's countries are facing limited fiscal resources, increased spending due to the COVID-19 pandemic context, poor public budgets, and high levels of indebtedness. To face these current challenges, a quick formula for optimizing the tax system must be found to meet the needs of the government system, but also the demands of citizens.

Tax revenues are the primary source of funding for public budgets. Frequently, tax revenues are measured as a percent of gross domestic product, indicating the ratio of a country's production that is received by the central and local authorities through taxes and fees. Figures in official reports of the European Union indicate a slight increase in the ratio of tax incomes in GDP (EU-27) in 2019, to an average of 40.1\% [1]. Fiscal pressure in the EU has increased steadily since 2010. In 2019, the fiscal pressure in the EU far exceeded the average level of OECD member states, 33.8\%, and other developed countries in the world (U.S.A., 24.5\%; Canada, 33.5\%; Australia, 28.7\%; Japan, 32\%; China, 28.5\%; etc.) [1]. On the other hand, the massive indebtedness of governments puts pressure on the tax system.

Many decision makers and economists are concerned about optimizing the tax structure. The introduction or modification of a tax obligation is a problem that must be a top 
priority because of the effects that are generated on several levels: financial, social, economic, and political. The fiscal policy can be used to search for the optimal taxation to constitute the budgetary revenues necessary to cover public expenditures. Any contemporary state's existence is inconceivable without an efficient tax system through yield for government and stress for taxpayers. The practical problem of any government is to establish the level of the optimal tax rate. For these reasons, the topics of taxation, in general, and tax optimization, in particular, are of significant interest to international researchers, out of the desire to propose relevant solutions to politicians. For instance, since 1975, there have been indexed in WoS more than 500,000 papers related to taxation $(\mathrm{TS}=(\operatorname{tax}))$ and their number gradually increased from almost 1000 papers in 1975 to over 36,000 papers in 2020.

Literature related to taxation can be considered rather as datasets that incorporate a variety of data, such as titles, publication years, authors, journals, keywords, and references. There is a large number of publications that contain a large amount of data inside such that it can be inefficient and even impossible to collect and compile it manually. The intellectual structure of any research field, including optimal taxation, can be identified through the quantitative examination of this information and its interconnections [2]. The credibility of research is known to be usually directly related to the method used [3]. The bibliometric analysis brings objectivity and legitimacy to the literature review process. The bibliometric analysis raises the accuracy of the scientific literature and avoids or reduces the bias of researchers on literature review [4]. Furthermore, by synthesizing the expertise of many researchers in the field, the research gains credibility.

The objective of this study was to explore the global scientific literature on optimal tax policy based on a scientometric inquiry to track its evolution in the conceptualization of tax optimum and trends in modeling optimal taxation. The multitude of research papers in taxation field and the rapidity with which they are developed lead to the need to measure the performances of scientific production in this field. The analysis of optimal taxation scientific production is necessary because (a) the science about optimal taxation is quickly advancing all over the world; (b) it is necessary to know at any time the tendencies and directions the optimal taxation literature is heading toward; (c) the large volume of papers published annually worldwide stimulates the development of bibliometric analysis; and (d) the rapid development of information technologies allows quantitative scientometric reviews. The research procedure was guided by the following research questions:

$R Q$ (1) What is the evolution of research production in the field of optimal taxation as volume and distribution?

RQ (2) What are the collaborative patterns between leading authors, institutions, and countries contributing to outputs of optimal taxation research?

RQ (3) Which papers, authors, and journals have had the most impact in the optimal taxation research field, and what are the connections existing between them?

$\mathrm{RQ}$ (4) What are the most attractive research topics related to tax policy optimization, and how have those research topics evolved?

We hope to find answers to these questions through this study and to provide comprehensive insight into optimal taxation research. To answer these questions, this paper is based on the Web of Science, Core Collection database, and the methods of scientometric analysis and knowledge mapping. Using CiteSpace software to conduct a systematic bibliometric review has a distinct advantage in that it can assist researchers in identifying more objective study subjects, track the evolution of a knowledge structure and its growth, and complement a traditional literature review [5]. Scholars can use CiteSpace software to fix attention on crucial data and characterize the knowledge components and evolution of a certain topic [6].

This paper does not constitute an extensive literature review; the paper explores the production of literature on the fiscal optimum by using visualization maps. The added value of this study is that it provides an in-depth bibliometric analysis of the evolution of the optimal taxation topic in the literature, and it creates an optimal taxation knowledge 
structure map. The lack of bibliometric analysis of the literature about optimal taxation studies emphasizes the novelty of our analysis. The current study provides direction and guidance to researchers interested in the field of optimal taxation. This bibliometric and visual study of optimal taxation research can assist new researchers in locating the most pertinent topics, countries, institutions, journals, authors, and articles within the field of optimal taxation. It makes a practical contribution by sharing relevant themes with the community and determining the future direction of research in optimal taxation to aid policy decision making and the formulation of potential tax legislative reforms.

Following this introduction, the paper's structure is as follows: in Section 2, a literature background is examined, considering the evolution of the optimal taxation field and paying specific attention to studies that try to measure and quantify the tax optimum and to other bibliometric analyses in the field. Then, Section 3 presents research methods, research sampling, and the software tools that were used. Next, in Section 4, the empirical results are displayed and analyzed using figures and tables, including descriptive analysis, co-authorship analysis, co-citation analysis, and co-word analysis. Finally, in Section 5, the study's primary findings, contributions, and future research directions are discussed, as well as the study's limitations.

\section{Literature Background}

Studying the literature background is important because it can provide an overview of the current framework, scientific principles, and empirical findings, as well as explaining the emerging trends in optimal taxation research. Optimization theory has evolved from providing generic solutions to optimizing problems in areas with or without constraints. The first approaches are aimed at optimizing activities at the individual level, and recent approaches aim at optimizing central, aggregate, macroeconomic activities. Optimization is the task of identifying one or more solutions that meet the goal of minimizing (or maximizing) one or more objectives that meet all existing constraints (if any) [7]. Equally important as the optimization task is building a mathematical or computerized model to solve the optimization problem. Optimization models try to express, in mathematical terms, the goal of solving a problem in the best way. Optimization models have been used over centuries since their purpose is so appealing. Systems of linear equations are most commonly used as algorithms for determining optimization models. Each model is based on numerical data, selected from different databases that process a series of variables that characterize public revenues. Simple mathematical manipulations are used to create income indicators, which are then combined with other economic and demographic variables to create a wide range of possibilities for measuring the tax system. Making choices to measure the fiscal optimum is an iterative process that involves testing certain hypotheses or possible reformulations of some central concepts. Revenue collection indicators are constructed as ratios of two variables. Explicit discussions on the measurement of tax revenues have led to better clarification of the concept and theoretical conclusions concerning the state's connection with society [8].

Economists' approaches to optimal taxation differ from those of social or non-social scientists, on the one hand, due to the attention paid to fiscal incentives and their effects, and on the other hand due to the awareness of the general balance [9]. There is a multitude of approaches to the optimal from a fiscal perspective, so concepts such as optimal tax, optimal tax rates, optimal tax revenues, optimal fiscal policy, optimal fiscal system, optimal fiscal administration, etc., can be discussed. Each individual can identify at least three reporting criteria in terms of "optimality" in tax matters. A first approach argues that an optimal tax system ensures that costs are kept to a minimum. A second approach argues that an optimal tax system is a system of fairness, equity, and impartiality. The third approach focuses on the fact that tax systems can be classified according to economic efficiency criteria, which is also the starting point for the optimal taxation theory. The optimal tax system is one that reduces tax revenue losses as much as possible [10]. 
The concept of "optimal taxation" describes attempts to combine the criteria of efficiency and fairness, considering the relative importance of each criterion, even if most individuals accept that both of these attributes in a tax system cannot be accomplished. An efficient tax system cannot necessarily be considered fair, nor can a fair tax system be efficient [11]. A good tax system makes it easier for taxpayers to comply with the law by reducing the time and effort required. The costs of the administrative machinery required for revenue collection, law enforcement, and law enforcement control are reduced by a quality fiscal system [12]. Optimality in the fiscal field can be translated into rules that taxes should respect and trust fairness, compliance, and neutrality. A reliable tax system is an optimal tax system, based on stability, certainty, and sufficiency in the generation of financial resources. It should be remembered that the tax system should not be viewed as isolated from other public policies. The fiscal system in correlation with other public policies, such as that of social welfare, can be used to outline results that reflect the country's economic and social vision. The tax system plays a crucial role in any macroeconomic framework. Achieving a fair tax system, in the context of the global economy, is a critical issue. The process of quantifying the fiscal optimum is meant to offer public decision makers different models and techniques necessary for managerial activities at the macroeconomic level.

Given that political guidelines have a significant effect on molding the features of the fiscal system, the approach to optimality in taxes can also be exercised in terms of political cycles and governing parties in a country. Taxes are significantly reduced in the election years and the year before the election, while their significant increase takes place in the first year after the election. Additionally, political ideology is important in establishing the optimal fiscal structure. Left-wing governments have been shown to count more on capital taxation than on income taxation. They rely on increasing the taxation of the consumption of goods and services [13].

One of the most debated topics is how tax system reduction and simplification lead to a rise in the economy. Adam Smith stated in 1776 that excessive tax rates undermine the tax base [14]. Arthur Laffer brought this idea to life in the 1980s. He created a curve demonstrating the connection between the tax rate and the tax base. Several economists continue to debate the general principle of the Laffer curve, even though the optimal tax rate is also a contentious issue. The reason why the tax system has everyone's attention is the fact that it directly affects more people than any other aspect at the public level.

The analysis of the specialized literature on optimal taxation highlighted the following central topics of interest: optimality in indirect taxation [15], optimality in direct taxation [16], optimality in fiscal and monetary policy, to which are added any other approaches to optimal taxation. It is noticeable the predilection of researchers in using a multitude of linear or non-linear econometric models, stochastic or not, static or dynamic, to justify the different aspects of optimal taxation. The optimal taxation approaches as econometric models may be relevant, but this does not exclude other types of approaches to optimal tax policy. The existing research on optimal taxation frequently implies that a country's capacity to implement sophisticated tax schemes exists, which is not always the case in developing countries [17].

In the current macroeconomic and COVID-19 pandemic context, it is necessary to draw up a viable strategy for financing the budget deficit and refinancing the public debt. The two goals cannot be achieved without a sustainable system of public finances. The ability of a government to maintain its existing spending, tax, and other related policies in the long run without compromising its solvency is referred to as fiscal sustainability [18]. An indicator of public finance sustainability can be considered an optimal tax system. Fiscal and budgetary sustainability cannot be achieved without collecting taxes in an optimal way. There are some real challenges regarding the sustainability of public finances, such as fiscal risk management, changing the tax system structure, increasing budget deficits, existence of fiscal institutions independent of political influence, demographic changes, laws to increase fiscal responsibility, unforeseeable international events, etc. Any fiscal or 
budgetary decision of the authorities must be, to a sustainable extent, capable of financing a deficient budgetary system.

Many scholars, practitioners, and policymakers around the world are interested in taxation studies. There has been a growing interest among researchers to explore many issues regarding taxation over the years. Despite so many studies, so far, there has been no study that identifies the knowledge structure and research development trends in the field of optimal taxation. We searched for bibliometric analysis on optimal taxation in databases such as Google Scholar, Scopus, ScienceDirect, Web of Science, and ProQuest. To the best of our knowledge, the literature on optimal taxation was not previously subject to bibliometric analysis. Some bibliometric studies provide data on a variety of fiscal themes (e.g., environmental tax [19], carbon tax [20], goods and service tax [21], tax evasion in Russia [22-24], tax avoidance [25], tax incentives [26], the influence of taxes on foreign direct investments [27], taxation literature in Malaysia [28], transfer pricing [29], tax competitiveness [30], and fiscal policy [31]). However, no one has conducted a complete evaluation of the optimal taxation literature from diverse perspectives using bibliometric analysis. It may be interesting to explore the field and to identify new dimensions of optimal taxation. Thus, we applied this well-known research method to a new research field: optimal taxation. It can become a valuable reference for future bibliometric and visual exploration of this field. In this regard, the study's purpose is to identify the key trends in scientific production of optimal taxation by bibliometric analysis, to find the key authors, research lines, and the phrases most often used in scientific articles.

\section{Research Methodology}

\subsection{Research Methods}

In general, systematic analysis includes rigorous techniques that allow for the replication of research procedures to minimize bias through a rigorous investigation of the reviewed publications. Scientometrics has a superior advantage over manual, traditional, or systematic reviews because scientometrics is performed to map and visualize scientific fields for new researchers, to assess and evaluate research performance, to breakdown scientific literature into disciplinary and sub-disciplinary structures, and to comprehend the discipline's structural, temporal, and dynamic evolution [32]. Bibliometric investigations follow a precise procedure that validates the data and provides a broad overview of the scientific field under investigation [33].

In this study, we employed two methodologies to perform a quantitative and visual analysis of optimal taxation research: bibliometric analysis and scientific mapping. The methodology diagram is presented in Figure 1. The goal of bibliometric analysis is to gather, describe, analyze, assess, and track published academic articles on a certain research topic. It is possible to identify patterns of a certain scientific discipline and study its output and performance based on authors, countries, organizations, and notable journals using bibliometric analysis [34]. Bibliometric analysis approaches are frequently employed in themes with a large number of publications throughout time; this method is often reliable and beneficial for studying novel scientific areas and detecting patterns for topics [35]. Bibliometric analysis provides a variety of information to researchers, editors, journals, and organizations about how relevant research topics have attracted attention over time, who the leading authors are, which studies have made outstanding contributions to the literature, and what aspects of the research topic stand out [36]. Bibliometric analysis is a basic, impartial, and unbiased analysis. 


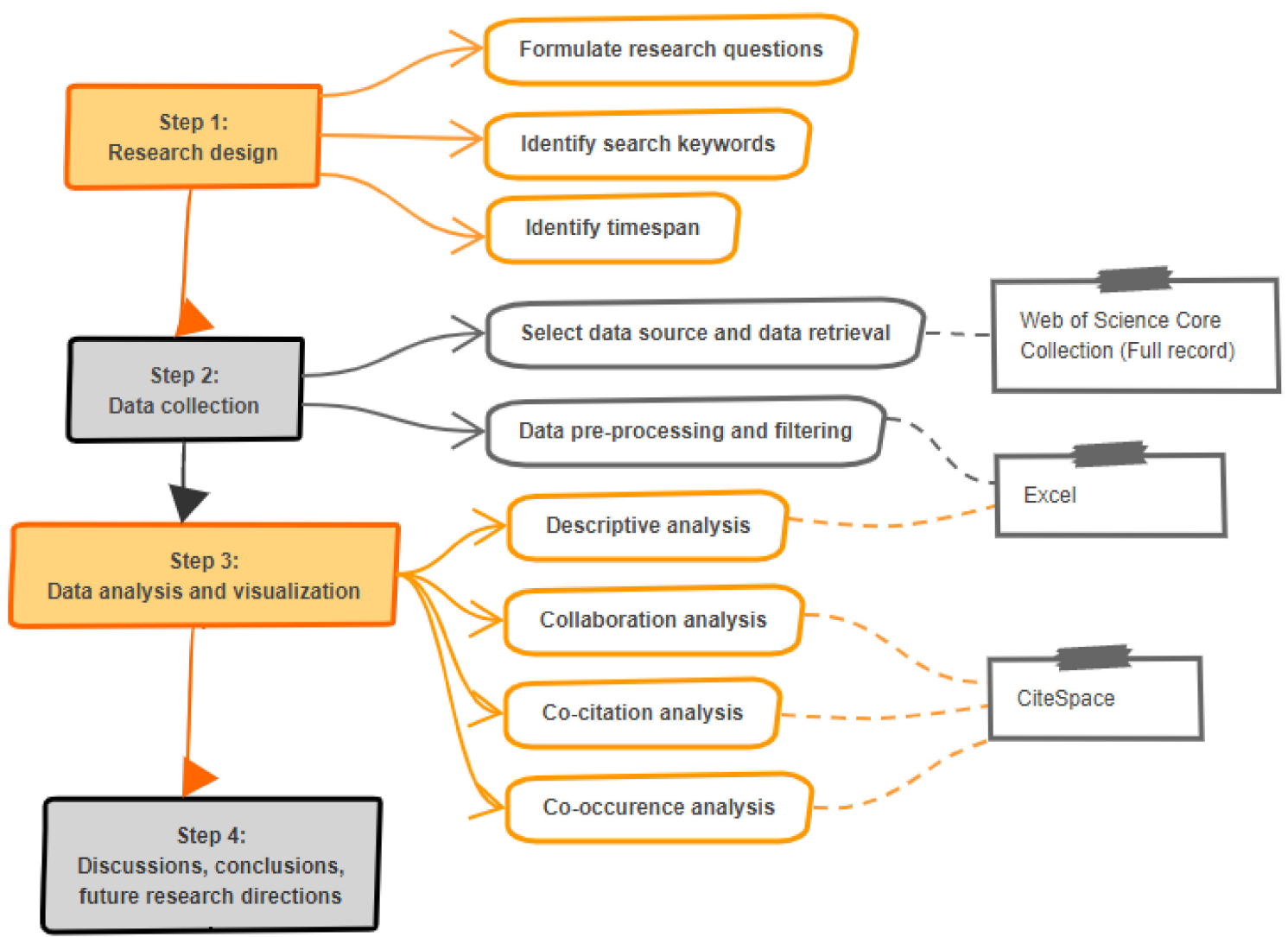

Figure 1. Methodology diagram. Source: created by authors using www.scketchboard.me (accessed on 7 June 2021).

Our preparation of the bibliometric analysis involved defining the research questions within the topic of optimal taxation. This was accomplished in the introduction part of the paper. We use descriptive analysis to investigate and identify the most influential journals, countries, and authors. Then, three other types of analysis are conducted. First, using the method of coauthor/collaborative analysis, we map networks of co-authorship in the optimal taxation field to reveal the social structure. Secondly, we carry on cocitation analysis, taking authors, journals, and documents as analysis units to reveal the optimal taxation field's intellectual framework. Co-citation analysis was conducted to determine the foundational literature of the study area, which are the most co-cited studies by the selected publication. When two papers are cited together in a publication, the degree of association between the cited documents is indicated [37]. The greater the number of co-citations a group of documents receives, the more probable it is that they are semantically connected. The network can be clustered into recurring themes or conceptual hotspots using co-citation analysis. Thirdly, a co-word / co-occurrence analysis was also carried out because it enables the determination of the conceptual structure and research themes of the study area. Nodes and links make up each network. The size of a node is related to the number of publications, and the links between nodes reflect their relationship and are proportionate to the strength of the connection. This study mainly used metrics of frequency or count, betweenness centrality, and citation burst to identify important nodes, which may be authors, journals, keywords, and documents [38]. The context and subjects of the investigation will determine which metric to utilize. At the network level, metrics provide information about the network's overall structure and ties. Individual-level metrics indicate a node's relevance in relation to all other nodes in a network, taking into consideration the various ways in which it interacts and communicates with the others.

Bibliometric maps are used in conjunction with bibliometric analyses to visualize the structure and its numerous linkages with other academic disciplines [39]. The scien- 
tific landscape can be mapped or shown to identify significant subjects, publications, or authors, as well as the relationships between them. Internal relationships between subject knowledge, development context, and evolution are revealed through scientific knowledge maps. Scientometric mapping, also known as bibliometric mapping, is a visual informatics technique that quantifies structural and dynamic elements of scientific research $[40,41]$.

\subsection{Data Sources and Data Collection}

Various bibliographic databases that contain diverse categories of publications are available online. Google Scholar, ProQuest, ScienceDirect, Web of Science, Scopus, and some other databases are all well known among scholars from several scientific disciplines. We used Web of Science as our data source for this study. The WoS is one of the most extensively used databases, with visuals and statistics for analyzing data about various study subjects, authors, document kinds, timeframes, countries, universities, and institutions, among other things. It also allows downloading the entire list of articles in a variety of formats, which are commonly utilized by mapping and data analysis applications. The rationale for using a WoS database is that the analysis tool used in this study, namely CiteSpace, was initially developed based only on a WoS database [42], which means that results generated by the use of WoS would be the most reliable and accurate. Moreover, to minimize potential information loss in eliminating duplications of publications from various sources, this study did not incorporate other databases.

Using advanced search, topic search (TS), and search phrases from the title, abstract, and keywords, the data for this study were collected from the Web of Science Core Collection. The Boolean operator "OR" was used to find papers that had both terms and obtain records that contained any of the query words. In the search query, an asterisk (*) was utilized to locate various word shapes. As of 15 July 2021, we searched for the different query words related to optimal taxation. There were no constraints on the subject area or the time period for which papers were searched; the goal was to include all relevant works, in order to give a full view of the study field, and to show its progress over time. A total of 29,893 documents were found as a result of the search. Among them there were many documents unrelated to our search area and irrelevant for our research questions, so we performed a second search by using as field tag only titles of publications (TI): $\mathrm{TI}=$ (optim* taxation) OR TI $=\left(\right.$ optim $^{*}$ fiscal polic $\left.{ }^{*}\right)$ OR TI $=\left(\right.$ optim $^{*}$ tax polic $)$ OR TI $=\left(\right.$ optim $^{*}$ tax rate $\left.^{*}\right)$ OR TI $=($ optim* fiscal rate* $)$ OR TI $=\left(\right.$ optim $^{*}$ tax system $\left.{ }^{*}\right)$ OR TI $=($ optim* fiscal

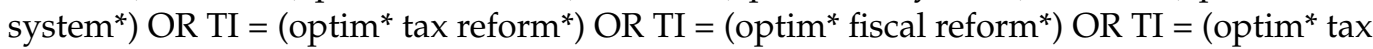
pressure) OR TI $=\left(\right.$ optim $^{*}$ fiscal pressure $)$ OR TI $=\left(\right.$ tax equilib $\left.{ }^{*}\right)$ OR TI $=\left(\right.$ fiscal equilib $\left.{ }^{*}\right)$ OR TI $=\left(\right.$ tax $^{*}$ optim $\left.{ }^{*}\right)$ OR TI $=($ fiscal optim $*$. As a result of the second search process, 2317 documents were retrieved, and then we performed an exact search and obtained 2245 documents. Table 1 contains a detailed description of the research sample. Among the 2245 publications, articles are the most common document type $(84 \%)$, followed by proceeding papers (12\%). Almost all the publications are in English (97\%). Other documents are written in other languages, such as French, German, and Spanish, which individually represent below $0.7 \%$ of the sample size.

Table 1. Literature search strategy.

\begin{tabular}{cc}
\hline Research Protocol & Details \\
\hline Database & Web of Science Core Collection \\
\hline Years (no timespan) & 1975-2021 July (>45 years) \\
\hline Time & 15 July 2021 \\
\hline Categories & All categories \\
\hline
\end{tabular}


Table 1. Cont.

\begin{tabular}{|c|c|}
\hline Research Protocol & Details \\
\hline Search words & 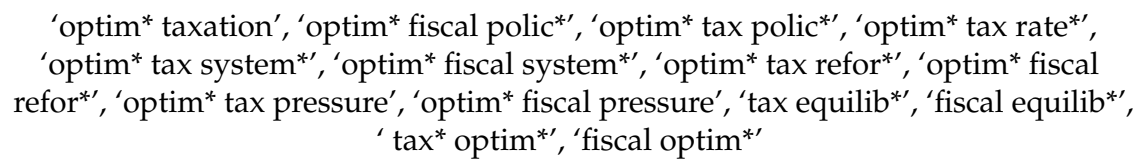 \\
\hline Languages & All languages \\
\hline Document type & All types of documents \\
\hline Sample size (cited papers) & 2245 publications \\
\hline Reference size (citing papers) & 23,527 \\
\hline Analysis software & CiteSpace \\
\hline
\end{tabular}

Then, journal articles and proceedings papers in English were filtered to improve the effectiveness in analyzing and interpreting the findings. After this step, the sample size contained 2023 publications in English. The retained documents were de-duplicated; in this step, only 1 publication was eliminated. Some exclusionary and inclusionary criteria were used during the pre-processing. The titles and abstracts of the publications found through the search were manually reviewed for relevance to the topic and to our research questions. Irrelevant documents were eliminated from the analysis (e.g., publications containing 'taxonomy', 'taxi', and 'taxus'). Additional relevant literature regarding the tax optimum from Laffer's point of view was included through a new search process in WoS, $\operatorname{tag}$ field TI $=($ Laffer $*$. The final dataset was composed of 1011 publications. The "Full Record" of these documents was downloaded (as Excel and Plain Text). For bibliometrics analysis and science mapping, these data were used as input. The final dataset of 1011 publications were accompanied by 11,278 citing articles (without self-citations) and were cited 17,361 times (without self-citations), giving an h-index of 66 .

\subsection{Visualization Tools}

Due to significant advances in scientometric visualization techniques, knowledge domains may now be easily depicted. For bibliometric analysis, to map and visualize massive scholarly datasets in the body of knowledge, a variety of visualization tools exists.

In the creation and construction of scientific domains, intellectual turning points are critical. CiteSpace assists in locating a missing research connection in a certain study subject and gaining a thorough understanding of the field by classifying these turning points [43]. CiteSpace (5.8.R1) is scientific visualization software based on Java for displaying patterns and trends in the scientific literature [44]. CiteSpace can be used to establish interrelationships between distinct components of a research topic using methods for comprehending term co-occurrence, citation, co-citation, and bibliographic coupling linkages, aside from providing information on significant thematic focus areas. The program can be downloaded for free at https: / / citespace.podia.com/ (accessed on 28 December 2021) [45]. The software includes information on various temporal trends connected to key publications that have affected the knowledge structure, as well as the altering thematic focus over time [46,47].

CiteSpace generates graphs with nodes and links as its output. The links reflect associations between nodes, while the nodes represent different types of entities (e.g., authors, journals, and references) [48]. CiteSpace uses co-authorship analysis to identify author collaboration and research power networks, document co-citation analysis to model the intellectual structure, co-occurring keywords to seek research topics and bursts of terms and citations to detect emerging trends [49]. The depiction of distinct colors, node locations, and node sizes makes it easy to identify nodes with a high citation frequency. Other technical details and measures of the concepts used by CiteSpace (e.g., burst detection, betweenness degree, and heterogeneity) can be found in the user guide [50]. According to 
Jia Q., Wei L., and Li X. (2019), CiteSpace has the following advantages: (a) it is effective for processing citation data from popular academic databases and open-access sources; (b) it allows the user to visualize and perform a variety of bibliometric analyses; (c) it is actively maintained and updated with new visual analytic features and theoretical developments as a Java-based and free software; and (d) it can support progressive network analysis based on time slicing strategy and interactivity [51]. Jiming X., Lulu W., Yuyan L., and Qingzhong D. (2017) highlighted some CiteSpace weaknesses: (a) it is mostly cited in citation analysis, making it difficult to analyze the relationships between various works; (b) by evaluating the major body of the research, it reduces the reliability of the results; and (c) it is primarily based on macro-research rather than micro-analysis [52].

CiteSpace's parameters in this work were established as follows: time-slicing was from 1975 to 2021, years per slice was one year, look back years (LBY) $=-1$, link retaining factor $(\mathrm{LRF})=-1$, and we kept the default values for text processing and links. Different node types were used depending on the sort of analysis performed. We also used temporal and structural metrics (e.g., citation burstiness, Sigma $\sum$, silhouette, rad Q, and betweenness centrality). All these metric indicators are explained in the CiteSpace Manual. The selection criteria were set as Top N $\%=100 \%$, Top $\mathrm{N}=50$, and g-index $=25$. This software provides a large number of visualization data, in addition to easy-to-understand interface options and a straightforward, user-friendly interpretation. CiteSpace tools use an economic analysis based on a map structure analysis to convert enormous amounts of literature data into viewable maps.

Alluvial Generator is a web application available at http:/ /www.mapequation.org/ apps.html (accessed on 31 August 2021). Alluvial Generator visualizes how clusters change between different networks in an alluvial diagram. The diagram reveals the structural transformation of networks [53].

\section{Results}

\subsection{Descriptive Analysis}

\subsubsection{Analysis of the Annual Distribution of Publications}

The distribution of publications across time is the first technique in scientometric analysis. The manner in which they were delivered can reveal information about a topic's prominence and the point at which it was first brought to the public's attention. The number of articles published each year in a certain study topic might represent the degree of conceptual development and where attention is focused in that field and is thus an essential indicator of its development and evolution [54]. The annual distribution of publications may indicate the advancement of optimal taxation research. The first nine papers were published in 1975, making the issue under consideration barely 46 years old, and a maximum share of $5 \%$ of total records belong to 2018. From 1975 to 2021, there were a total of 1011 documents published in the WoS databases (July). The literature's overall trend shows an increase in the number of publications, indicating that optimal taxation research is rising and remains a hotspot. Over the past 46 years, the annual number of publications on tax optimization has increased, but with some oscillations, as shown in Figure 2. After nearly two decades, the lowest output was in 2000, with only 7 publications, while the highest output was in 2018, with 51 publications. Based on the number of published papers, this scientific field has experienced three stages of development: 1975-1986, 1987-2005, and 2006-2020. Furthermore, there are six jumps in which the number of articles is more than 1.50 times higher than the previous year's equivalent value $(1982,1986,1994,2001,2013$, and 2018). 


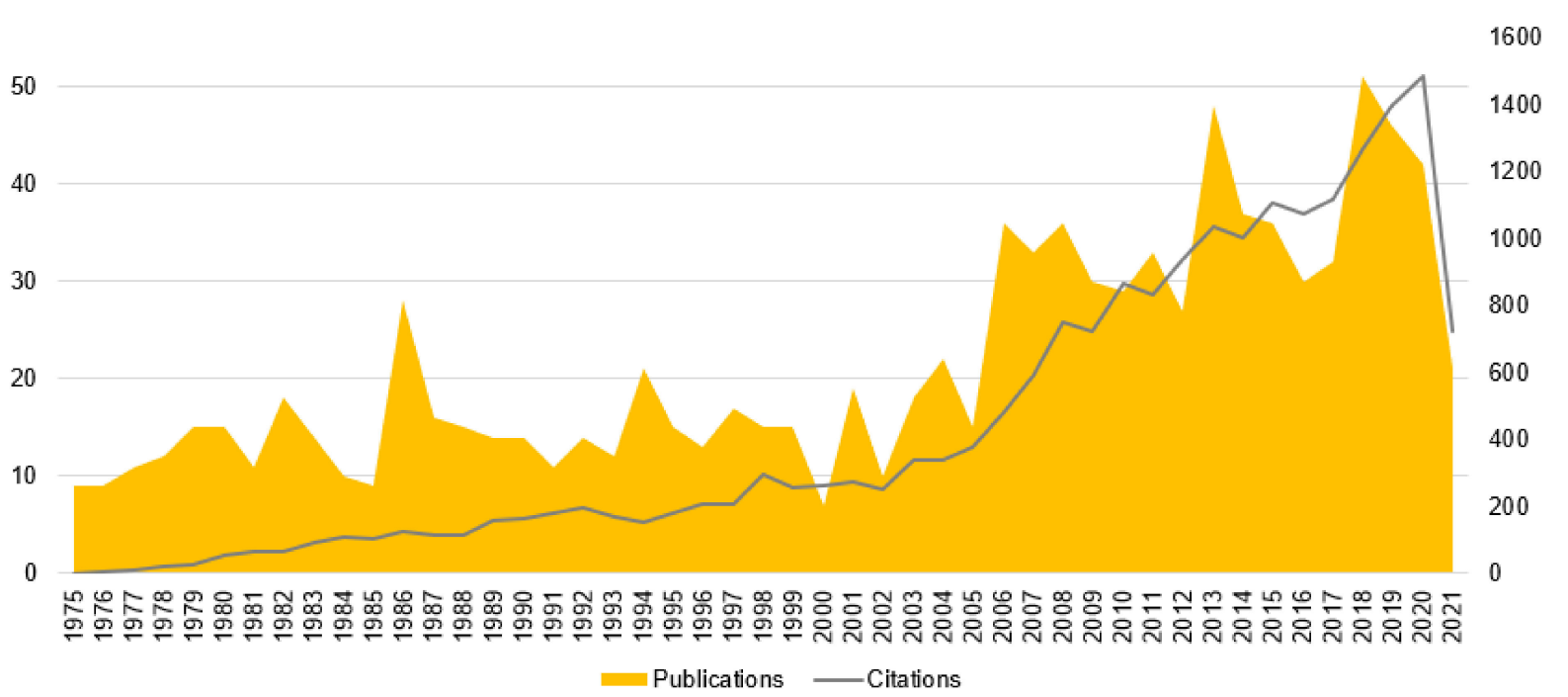

Figure 2. Annual variations of literature outputs related to optimal taxation from 1975 to 2021. Source: created by authors.

The first stage 1975-1985 (11 years) represents the beginning of research publications on optimal taxation. An average number of 12 articles were published each year, so entire period contributed 133 papers to the literature written by 143 authors. In the second stage 1986-2005 (20 years), there was a significant growth in the number of publications on the subject of optimal taxation. This occurred in 1986 when 35 authors studied tax optimization and published 28 articles. Over two decades, 311 articles about optimal tax were published and indexed in WoS, with an average of 16 publications per year, and having 365 persons as authors. The third stage 2006-2020 (15 years) brings an increase in the average number of publications to 36 per year, which means a total of 546 publications written by 746 persons. The topic of optimal taxation is currently generating a lot of buzz around the world. The past 3 years (2018-2020) account for 139 publications about optimal taxation and represent $13.70 \%$ of total records. Research on optimal taxation is predicted to become increasingly exhaustive and improve as relevant studies progress. This implies that an increasing number of experts have acknowledged the relevance of this research subject. In summary, the research on tax optimization is an increasingly popular research topic.

The distribution of nations studying optimal taxation could be better understood if the country information was analyzed based on the affiliations of the writers. The 1011 publications examined in this report came from 53 different nations. The United States of America (U.S.A.), the United Kingdom (U.K.), Canada, Germany, France, China, Japan, Sweden, Italy, and Australia are the top ten countries in the world when it comes to research contributions to the topic of optimal taxation. The U.S.A. is the leading country where article outputs focus on studying optimal taxation and tax policy. The U.S.A. records 399 publications, which represent $39.40 \%$ of total publications, which is three times more than the U.K. (rank 2). The U.K. holds the second position with 130 publications (12.30\%), followed by Canada and Germany with over 80 publications each, and France with 63 publications. The remaining aforementioned countries record approximately 40 to 50 publications each. Data show that $96 \%$ of all analyzed documents have as their origin country the members of the top 10 countries. There are 26 countries where the number of publications is below or equal to 3 .

\subsubsection{Analysis of Authors}

To some extent, a researcher's devoted efforts can be reflected in the number of articles he or she has published. A total of 1176 different scholars was found in our investigation. Between 1 and 20 papers were published by each of them. Table 2 shows that the author with the most output in optimal taxation studies is Aronsson T., whose research focuses on 
optimal income taxation. The other top nine authors have diverse research focuses, mainly in the field of optimal linear or non-linear income taxation. The top ten most productive authors accounted for $9.10 \%$ of all publications.

Table 2. Top 10 most productive authors in optimal taxation research.

\begin{tabular}{cccccc}
\hline Rank & Authors & Pubs & $\%$ & h-Index & Main Focuses \\
\hline 1 & Aronsson T. & 20 & 1.98 & 17 & optimal income taxation \\
\hline 2 & Gahvari F. & 14 & 1.39 & 18 & $\begin{array}{c}\text { optimal commodity taxes, optimal taxation of } \\
\text { housing }\end{array}$ \\
\hline 3 & Weymark J.A. & 13 & 1.29 & 21 & optimal nonlinear income taxation \\
\hline 4 & Brett C. & 12 & 1.19 & 9 & optimal nonlinear income taxation \\
\hline 5 & Boadway R. & 11 & 1.09 & 25 & optimal linear income taxation \\
\hline 6 & Cremer H. & 11 & 1.09 & 23 & optimal commodity taxes, optimal taxation of \\
\hline 8 & Tuomala M. & 11 & 1.09 & 13 & optimal nonlinear income taxation \\
\hline 9 & Slemrod J. & 10 & 0.99 & 40 & optimal tax system \\
\hline 10 & Pestieau P. & 9 & 0.89 & 21 & optimal linear income taxation \\
\hline & Wilson J.D. & 9 & 0.89 & 21 & optimal commodity taxes, optimal income \\
taxes
\end{tabular}

Note: Pubs = number of publications; \% = share in total analyzed documents (1011); h-index is based on the Web of Science Core Collection citations of the publications calculated for each author. Source: created by authors using the analyzed database.

The data indicate that Aronsson T. dominated the list of publications. He is affiliated with Umea University (Sweden) and has published 20 papers related to optimal taxation. Gahvari F., University of Illinois System, ranks second with 14 papers. There are other productive authors in this field, including Weymark J.A., Boadway R., and Slemrod J. among others. It is also worth noting that Gahvari F. and Cremer H. were co-authors on a number of articles. These top ten authors had 120 articles in total, which represents $10 \%$ of total publications. However, the majority of authors $(94.40 \%)$ produced fewer than three publications, implying that only a small number of researchers made significant contributions to this subject. It should be pointed out that the total number of authors exceeds the number of articles on optimal taxation owing to scientific collaboration among authors.

\subsubsection{Analysis of Journals}

Journal analysis is also a worthwhile read because it aids in the identification of the most appropriate journals for publishing relevant findings. All 1011 tax optimizationrelated publications were published in 265 distinct journals or conference proceedings, according to the source journals. During the research period, just one article on tax policy optimization was published in 171 journals/conference proceedings. Moreover, $80 \%$ of 265 journals contributed to the research field with fewer than three publications. Table 3 shows the top 10 most prolific journals, which have published 405 articles, accounting for $40 \%$ of the total number of articles published in this subject (2/5). The top-ranked journal is the Journal of Public Economics, which dominates the ranking with a total of 140 published articles, accounting for $13.80 \%$ of all optimal taxation publications, almost three times more than the second position. The following two journals are Economic Letters and Journal of Public Economic Theory, which both have over 40 publications. The rest of the leading journals have published over 20 articles on optimal taxation, even if two of them have had an impact factor larger than the top journal. 
Table 3. Top 10 productive journals in optimal taxation research.

\begin{tabular}{|c|c|c|c|c|c|c|c|}
\hline Rank & Journals & Pubs & $\%$ & Category & JIF & Average JIF & Quartile \\
\hline 1 & Journal of Public Economics & 140 & 13.85 & Economics-SSCI & 3.11 & 2.11 & Q1 \\
\hline 2 & Economics Letters & 47 & 4.65 & Economics-SSCI & 2.10 & 1.17 & Q2 \\
\hline 3 & Journal of Public Economic Theory & 43 & 4.25 & Economics-SSCI & 1.46 & 1.01 & Q3 \\
\hline 4 & International Tax and Public Finance & 34 & 3.36 & Economics-SSCI & 1.34 & 0.94 & Q3 \\
\hline 5 & Scandinavian Journal of Economics & 29 & 2.87 & Economics-SSCI & 1.70 & 1.36 & Q3 \\
\hline 6 & Journal of Monetary Economics & 24 & 2.37 & Economics-SSCI & 4.27 & 2.79 & Q1 \\
\hline 7 & Journal of Economic Dynamics Control & 23 & 2.28 & Economics-SSCI & 1.59 & 1.37 & Q2 \\
\hline 8 & Review of Economic Studies & 23 & 2.28 & Economics-SSCI & 6.35 & 4.90 & Q1 \\
\hline 9 & Oxford Economic Papers New Series & 21 & 2.08 & Economics-SSCI & 1.29 & 1.00 & Q3 \\
\hline 10 & Public Finance Finances Publiques * & 21 & 2.08 & - & - & & - \\
\hline
\end{tabular}

Note: Pubs = publications; \% = share in total analyzed documents (1011); SSCI = Social Science Citation Index; JIF = Journal Impact Factor according to Journal Citation Reports 2020 (calculated from data indexed in the Web of Science Core Collection). Average JIF is calculated as average of yearly JIF values from 2016 to 2020). Quartile = category ranking by JIF. * This journal appears as indexed between 1975 and 1994, we cannot find journal metrics for this journal. Source: created by authors using the analyzed database.

\subsection{Collaboration (Co-Authorship) Analysis}

Modern academic research relies heavily on scientific collaborative networks. Coauthorship analysis is a popular method for analyzing and evaluating scientific collaboration patterns. Researchers are no longer individuals, but rather a part of teams that combine complimentary abilities and multidisciplinary techniques to achieve common aims. The use of social network analysis and co-authorship networks to assess collaboration patterns and identify prominent scientists and companies is becoming more common [55]. Scientific collaboration is defined as the interaction between two or more scientists in a social framework that promotes the sharing of meaning and the completion of tasks related to a mutually shared aim [56]. In this section of analysis, we identified the leading academics and research institutes that had a critical position in distributing information on tax optimization. Because visualization lends meaning to the analysis, we employed networking maps. Each network actor is typically represented by a circle, with the size and/or color of the circle reflecting one or more of the actor's characteristics.

\subsubsection{Analysis of Authors}

The author cooperation network can assist in identifying authors who make significant contributions and revealing author collaboration relationships. The co-authorship network was generated by CiteSpace with the following parameters: Top N\% $=100 \%$, Top $N=$ 50 per year (1975-2021), LRF $=-1, \mathrm{LBY}=-1$. We did not prune the sliced networks. After running the software, the outcome was a 797-node, 329-link network of co-authors, shown in Figure 3. Each node represents an author, as indicated by the node label, whose font size reflects the author's number of publications. The connections between each pair of nodes represent scientific collaborations formed by co-authorship. The thickness of the link reflects the extent of collaboration between the two authors. The thicker the linkage, the higher the level of cooperative relationship. 

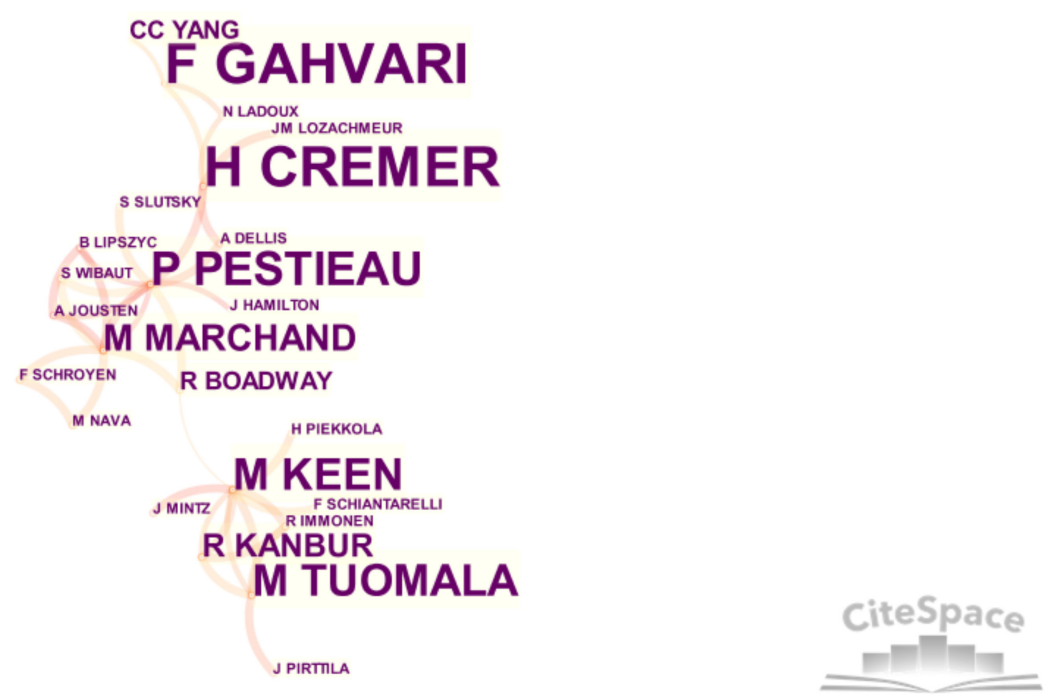

Figure 3. Collaboration network map of authors for optimal taxation research. Source: derived by authors from CiteSpace.

With regard to cooperative relationships, the density of the network tends to zero, indicating that the authors' group has not created strong collaborative relationships. Gahvari F., Cremer H., and Craig B. were the top three collaborative authors with 11 publications each as co-author. Aronsson T. (10 publications), Lehmann E. (8), Wilson J.D. (7), Saez E. (7), Rabindra R. (7), Jacobs B. (7), and Pestieu P. (7) follow to form the top ten most collaborative authors. The major cooperation networks are not all linked together, and there are a lot of small cooperative networks (529 clusters), showing that the overall cooperation for optimal taxation research was neglected. Collaboration is a crucial step in the growth of scientific communities; the author network in this field is divided into distinct qualitative groups.

In the field, there were two closely working research teams, as indicated in Figure 3. They are centered around key authors from the top 20 most collaborative authors with more than four papers on optimal taxation as co-authors. The research team, led by Gahvari F., includes Cremer H., Pestieu P., and others, mainly studying optimal taxation influenced by externalities, uncertainty, or tax evasion [57-59]. Tuomala M. is the leader of the second study team, which includes Keen M., Kanbur R., and others. They mainly studied the optimal non-linear income taxation [60-62]. There are no authors for which the betweenness centrality is nonzero. Only 56 scholars are co-authors in at least three publications; hundreds of scholars have one or two collaborative research documents in the optimal taxation field. From the perspective of citation burst, four burst authors have a duration of 6 to 10 years: Gahvari F., 1993-1999; Cremer H., 1993-2004; Aronsson T., 2009-2017; and Rabindra R., 1985-1991. All in all, we found few authors with strong collaboration.

The analysis of the number of authors over time reveals an upward trend year after year. The number of authors interested in the optimal taxation field has grown steadily from 15 persons before 1980 to over 50 persons after 2010. The 1980s and 1990s are characterized by an average number of authors of 20 persons conducting research in the optimal taxation field. In the past decade, the number of authors fluctuated from a minimum of 54 authors in 2012 and 107 authors in 2018. It should be mentioned that the number of authors exceeds the number of articles, meaning that some of them are co-authors. These data show an increasing level of co-authorship. Our findings demonstrate the hypothesis of Rath and Wohlrabe (2016), who identified an upward trend of authorship across all sub-disciplines in economics and across different quality levels of journals. They also found that the higher the impact of a journal, the higher the likelihood of more co-authors [63]. 


\subsubsection{Analysis of Institutions}

To investigate core institutions and cooperation relationships related to optimal taxation research, we came up with a network of co-authors' institutions. The CiteSpace parameters were the same as for the co-authorship network. Figure 4 shows the visualization maps of the institutions that published research on optimal taxation. An organization's font size is related to the number of publications it produces. The relationship and frequency of cooperation between two institutions are represented by the connection and thickness between nodes. We can see how these institutions construct a complicated web of interconnections, suggesting close collaboration. The importance of a given node in a network is represented by its centrality. As a result, the more central an institution is, the more publications it has with others. The visualization map for institutions' collaboration where optimal taxation research has occurred was produced without the use of the pruning parameter. The network had 505 nodes and 433 links when the software was run, and the density was almost zero. By clustering, institutions are grouped in 242 clusters with a sufficient clustering configuration level and appropriate division of the institutions.

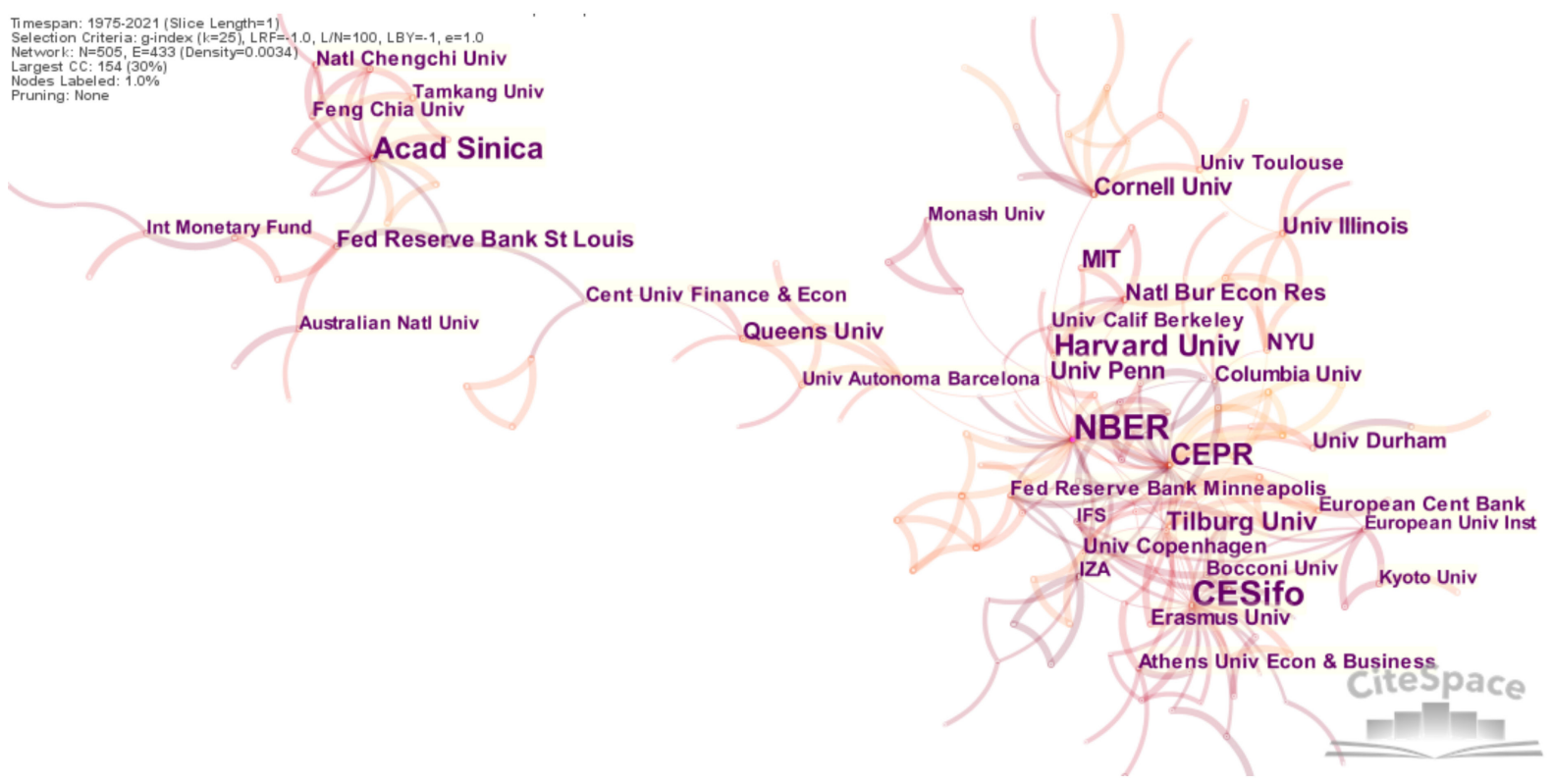

Figure 4. Collaboration network map of institutions for optimal taxation research. Source: derived by authors from CiteSpace.

We can see from Figure 4, that there are several research networks contributing to the optimal taxation field. NBER (National Bureau of Economic Research), CEPR (Centre for European Policy Research), IZA (Institut für die Zukunft der Arbeit), and CESifo (Center for Economic Studies) manage the most cited and downloaded working paper series on RePEc [64]. They are networks of economists. Submitting papers to the series is only allowed for members of the corresponding networks and joining the network is only possible by invitation. Once an author is a member of a specific network, they are free to submit any working paper [64]. If we ignore these institutions, we noticed that Harvard University from the U.S.A. (14 publications), Academia Sinica from Taiwan (14), and Umea University from Sweden (13) are the top three most impactful and collaborative institutes of optimal taxation-related publications. Other productive institutions are Tilburg University from the Netherlands (9), the Catholic University of Louvain from Belgium (9), Massachusetts Institute of Technology from the U.S.A. (8), and Mount Allison University from Canada (8). The institution with the highest centrality is Academia Sinica (Taiwan, 12). In terms of the Sigma value, the University of Western Ontario (Canada, 0.07), Queen's University (Canada, 0.06), and Shandong University (China, 0.05) are the top three institutions. Furthermore, the citation burst of institutions can be a signal of institutions that 
publish a large number of papers in a short period of time. Except CESifo, there is one institution with citation bursts: Umea University (10 years, 2003-2013).

\subsubsection{Analysis of Countries}

Co-authorship analysis by country is a common type of co-authorship analysis. Cooperation between countries is still in its infancy, but it should be supported in order to internationalize and expand research in the field. It might reflect the level of communication between countries, including the countries that are impactful in this domain. Figure 5 illustrates the countries' collaborative network of optimal taxation-related publications. The parameters of CiteSpace were the same as for the co-authorship network. A study of cross-national collaboration uncovered 55 nodes with 155 links and a network density close to zero. The most dominant countries are represented by nodes of the largest size. The node-to-node links represent the cooperative relationships between these countries' institutes. The thickness of the linkages and the distance between the nodes show the level of cooperation between countries. The country's collaborative network may reflect the focus on optimal taxation research at the national level. There were 294 citation counts in the largest connected country collaboration network. The United States was instrumental in creating academic exchanges and collaboration in the field of optimal taxation research.

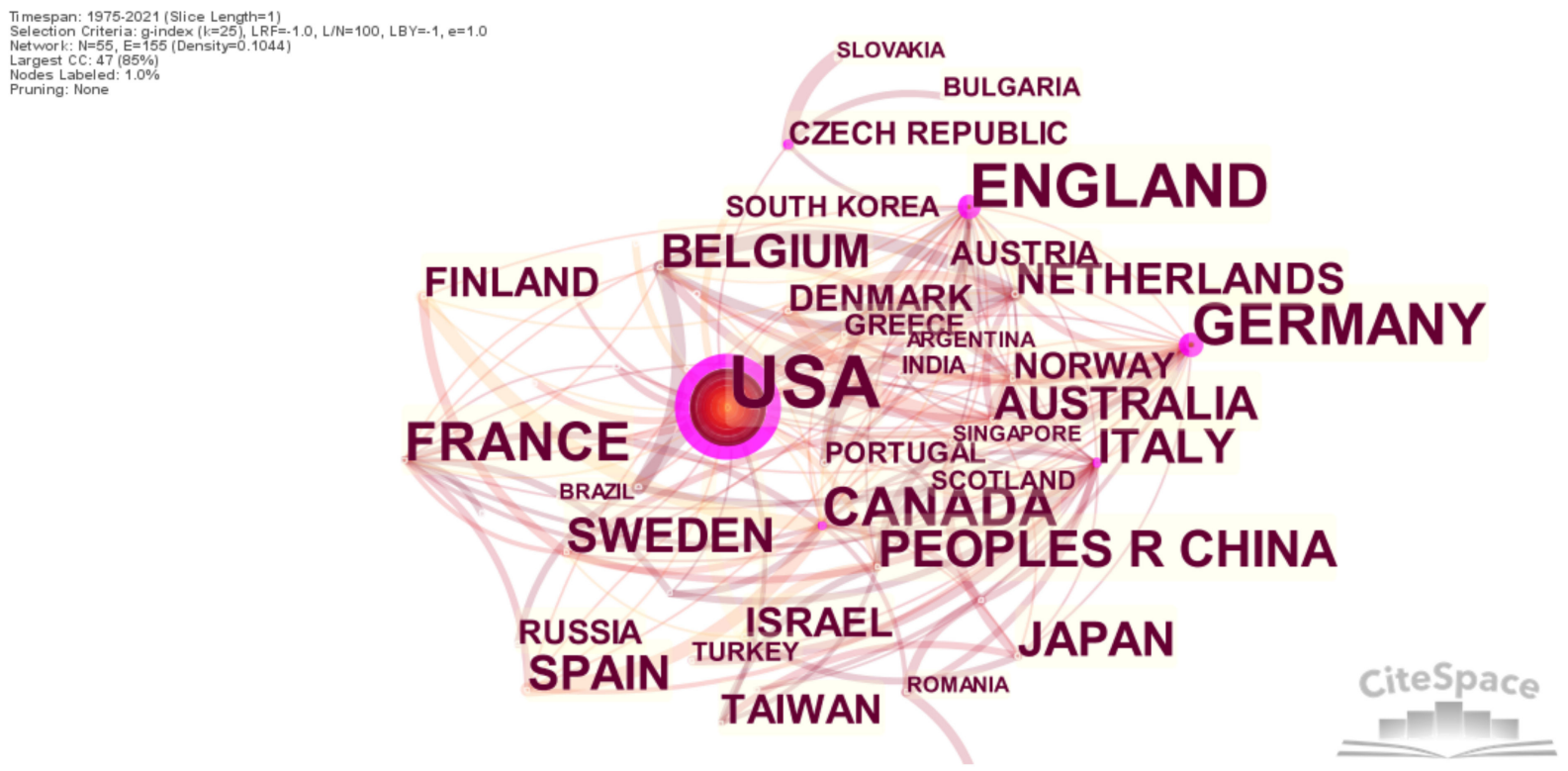

Figure 5. Collaboration network map of countries for optimal taxation research. Source: derived by authors from CiteSpace.

The center of research for the topic of optimal taxation is located in the United States of America (294 citation counts), as shown in Figure 5, followed by England (94), Germany (78), France (59), and Canada (58). The largest number of research institutes from Asia studying optimal taxation are in China (48), followed by Japan (34). The degree of centrality of each node revealed that the United States is the most central, with an intermediary role and substantial dominance for tax optimization research in the network configuration. The findings clearly demonstrate a lack of authority and influence, as well as a lack of partnership and connection among nations in the field.

\subsection{Co-Citation Analysis}

Citation analysis is a method for determining or surveying the patterns and framework of a certain body of cognition. Additionally, it is a method for identifying the primary participants. Citation analysis provides useful methods for assessing the contributions, productivity, communications, and linkages of authors and journals. 


\subsubsection{Analysis of Cited References}

There are many distinct indicators in bibliometrics analysis, and one of the most important citation networks in this form of study is co-cited references. When two documents (cited documents) are cited together by a third document, this is referred to as reference co-citation (citing document). This study can aid in the identification of significant research areas, the discovery of useful references, and better knowledge of the field's evolution. The reference analysis identifies and emphasizes the authors of the papers with the most citations and that are regarded as essential references in the scientific field.

Based on the visualized analysis resulted after pruning the Pathfinder/Pruning sliced network, we generated a co-citation network of 1243 nodes, 5811 links, and a density close to zero, as shown in Figure 6. According to the co-citation analysis, the key publications in the optimal taxation field are Mirrlees J.A. (1971), Atkinson A.B. (1976), Chamley C. (1986), Judd K.L. (1985), and Diamond P.A. (1971). Table 4 lists the top 15 articles in the subject of optimal taxation with the most citations. The co-cited document with the highest centrality value is published by Atkinson A.B. (1976). It is followed by Ramsey F.P. (1927), Lucas R.E. (1983), Diamond P.A. (1971), and Atkinson A.B. (1974). These papers are the most influential in the optimal taxation research field. Timespan: $1975-2021$ ( Slice Length=1)
Selection CCriteria: g-index ( $k=25$ ) LRF $=-1.0, \mathrm{~L} / \mathrm{N}=10, \mathrm{LBY}=-1, \mathrm{e}=1.0$
Network: $N=1243, \mathrm{E}=5811$ (Density $=0.0075$ ) lodes Labeled: $50 \%$
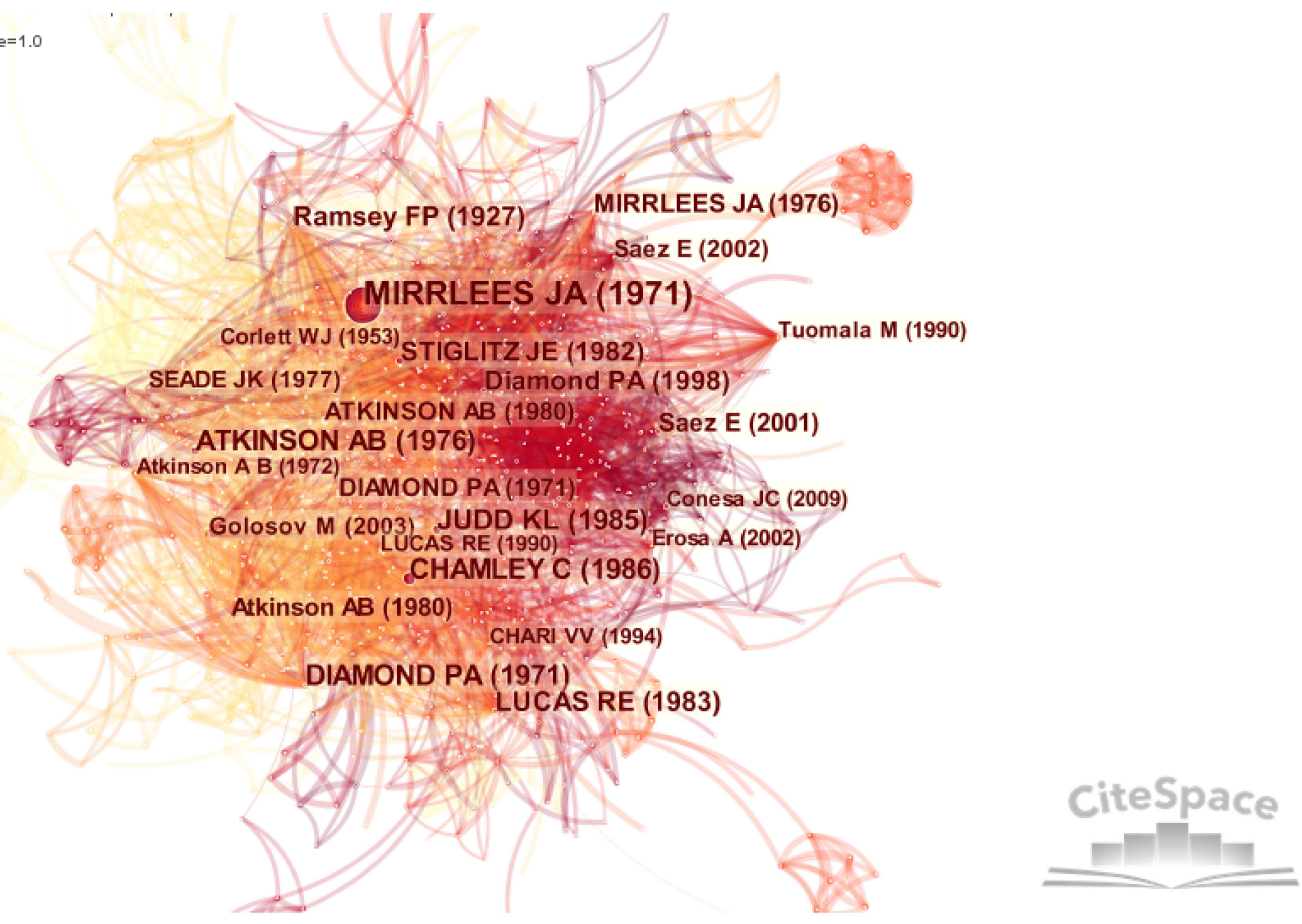

Figure 6. Visualization of reference co-citation networks for optimal taxation research. Source: derived from CiteSpace by authors. 
Table 4. Distribution of the top 15 cited references in optimal taxation research.

\begin{tabular}{|c|c|c|c|c|c|c|c|}
\hline Rank & Reference & Journal & Year & Frequency & Centrality & Burst & Sigma \\
\hline 1 & Mirrlees J.A. & Review of Economic Studies & 1971 & 277 & 0.11 & - & 1.00 \\
\hline 2 & Atkinson A.B. & Journal of Public Economics & 1976 & 129 & 0.23 & - & 1.00 \\
\hline 3 & Chamley C. & Econometrica & 1986 & 127 & 0.04 & - & 1.00 \\
\hline 4 & Judd K.L. & Journal of Public Economics & 1985 & 102 & 0.04 & 3.97 & 1.18 \\
\hline 5 & Diamond P.A. & American Economic Review & 1971 & 96 & 0.13 & 4.10 & 1.67 \\
\hline 6 & Stiglitz J.E. & Journal of Public Economics & 1982 & 85 & 0.03 & 6.14 & 1.23 \\
\hline 7 & Ramsey F.P. & Economic Journal & 1927 & 85 & 0.17 & - & 1.00 \\
\hline 8 & Lucas R.E. & Journal of Monetary Economics & 1983 & 78 & 0.15 & 4.52 & 1.87 \\
\hline 9 & Diamond P.A. & American Economic Review & 1998 & 76 & 0.03 & 3.90 & 1.11 \\
\hline 10 & Saez E. & Review of Economic Studies & 2001 & 71 & 0.01 & 12.00 & 1.17 \\
\hline 11 & Diamond P.A. & American Economic Review & 1971 & 68 & 0.06 & 17.13 & 2.54 \\
\hline 12 & Atkinson A.B. & Lectures on Public Economics & 1980 & 63 & 0.08 & 32.11 & 10.83 \\
\hline 13 & Mirrlees J.A. & Journal of Public Economics & 1976 & 53 & 0.06 & - & 1.00 \\
\hline 14 & Atkinson A.B. & Lectures on Public Economics & 1980 & 52 & 0.04 & 9.33 & 1.47 \\
\hline 15 & Seade J.K. & Journal of Public Economics & 1977 & 47 & 0.04 & 4.95 & 1.23 \\
\hline
\end{tabular}

Source: derived by authors from CiteSpace.

Mirrlees J.A. (1971) explored the optimal income taxation hypothesis by creating an econometric model based on seven assumptions. He believes that the design of the ideal earned-income tax schedule is highly dependent on the population's skill distribution and the income-leisure preferences assumed. Estimating real economies is difficult [16]. Atkinson A.B. and Stiglitz J. (1976) discussed the structure of taxes, dividing them into direct and indirect taxes as an alternatives approach to income distribution [65]. Chamley C. (1986) investigated how taxes function as a fiscal instrument in the broad problem of secondbest with perfect foresight and no uncertainty [66]. Judd K.L. (1985) demonstrated that redistribution through capital income taxation may be ineffective sooner or later in a utilitymaximizing model of capital accumulation [67]. Diamond P.A. and Mirrlees (1971a) studied the relationship between optimal taxation and public production [68]. Ramsey F.P. (1927) contributed to taxation theory by tackling a tax problem in his paper: a specific income is to be increased by proportional taxes on different types of income, the taxes on different incomes being possible at different rates; what adjustments should be made to these rates so that the loss of utility is kept to a minimum [15]? Lucas R.E. and Stokey N. (1983) presented that the optimal tax policy is consistent in time. The authors stated that fully binding debt of a sufficiently rich maturity and risk structure can be produced, and that the optimal debt policy is unique [69].

We built a co-citation network with 11,278 papers to better understand how the representative literature clustered. It should be noted that the references cited in the 1011 publications are included in this list of 11,278 papers. The log-likelihood ratio test (LLR), which is CiteSpace's default algorithm, was utilized to extract the cluster labels in this study. The modularity $Q$ value suggests a solid clustering structure in this created network. However, because there are not many tiny clusters, the mean silhouette value was rather high. The number of the largest cluster is \#0, and the number of the smallest one is \#19. The dimension of a cluster is determined by the quantity of published papers within it and varies between 193 papers in cluster \#0 and 6 papers in cluster \#19. All of the clusters displayed considerably high silhouette values and indicated high grouping quality. Cluster $\# 1$ has the lowest silhouette of 0.75 (size = 149) and cluster \#16 has the maximum silhouette value of 1 (size $=9)$.

The two largest clusters were chosen for further investigation since their silhouette score was high enough. With 193 components, the largest cluster (\#0) is the most populous. It is referred to as capital income. The most in-action citer of the cluster is Jacobs B. (2013), who provided a perspective on the optimal tax system as a dual one where labor and capital 
incomes are taxed separately [70]. He is followed by Krueger D. (2016) and Domeij, D (2005). Krueger D. and his colleague Ludwig A. characterized the optimal mix of progressive income taxes and education subsidies and argued that a large education subsidy and a moderately progressive labor income tax constitute part of the optimal fiscal constitution once household college attendance decisions are endogenous and transitional dynamics are modeled explicitly [71]. In his paper, Domeij D. shows that the optimal capital tax is generally non-zero and can be utilized to adjust for labor market tightness distortions when the government is restricted by capital and labor taxation [72].

With 149 individuals, the second-largest cluster is cluster \#1. Endogenous participation is its label. The cluster's most active citer is Boadway R. (2013), followed by Findeisen S. (2016) and Kanbur R. (2013). Boadway R. and Tremblay J.F. in their article consider that the structure of marginal and average tax rates can vary considerably depending on whether labor supply varies along the intensive or extensive margin, whether wages are endogenous, whether there is unemployment and whether it is temporary or permanent [73]. Findeisen S. and Sachs D. studied the implications of endogenous education decisions before labor market entry on Pareto optimal tax policies in a dynamic environment with heterogeneous agents and uncertainty [74]. Kanbur R. and Tuomala M. tried providing a set of three answers to the basic question: how does relativity affect the structure of optimal nonlinear income taxation [61]?

Burst term refers to a spike in the use of a keyword or citation of a publication over a period of time, and it is critical to define the research frontier for a specific scientific subject [48]. The larger the burst, the faster the frequency of citations grows. A cited document burst occurs when the number of document citations suddenly increases. The top 15 cited documents with the strongest citation bursts in different time periods are listed in Figure 7. It displays the date and duration of each document's first citation. The blue lines represent the whole study period, while the red lines represent the duration of each paper's citation bursts. It reflects the document's continued significance in the field of optimal taxation research.

References

DIAMOND PA, 1971, AM ECON REV, V61, P261

PHELPS ES, 1973, Q J ECON, V87, P331, DOI 10.2307/1882009, DOI

SHESHINSKI E, 1972, REV ECON STUD, V39, P297, DOI 10.2307/2296360, DOI

STERN NH, 1976, J PUBLIC ECON, V6, P123, DOI 10.1016/0047-2727(76)90044-X, DOI

ATKINSON AB, 1980, LECTURES PUBLIC EC, V0, P0

LUCAS RE, 1990, OXFORD ECON PAP, V42, P293, DOI 10.1093/oxfordjournals.oep. a041948, DOI

Atkinson AB, 1980, LECT PUBLIC EC, V0, P0

Erosa A, 2002, J ECON THEORY, V105, P338, DOI 10.1006/jeth.2001.2877, DOI

Golosov M, 2003, REV ECON STUD, V70, P569, DOI 10.1111/1467-937X.00256, DOI

Kocherlakota NR, 2005, ECONOMETRICA, V73, P1587, DOI 10.1111/j.1468-

0262.2005.00630.x, DOI

Saez E, 2001, REV ECON STUD, V68, P205, DOI 10.1111/1467-937X.00166, DOI

Conesa JC, 2009, AM ECON REV, V99, P25, DOI 10.1257/aer.99.1.25, DOI

Chari VV, 1999, HBK ECON, V15, P1671

Mankiw NG, 2009, J ECON PERSPECT, V23, P147, DOI 10.1257/jep.23.4.147, DOI

Piketty T, 2013, HBK ECON, V5, P391, DOI 10.1016/B978-0-444-53759-1.00007-8, DOI

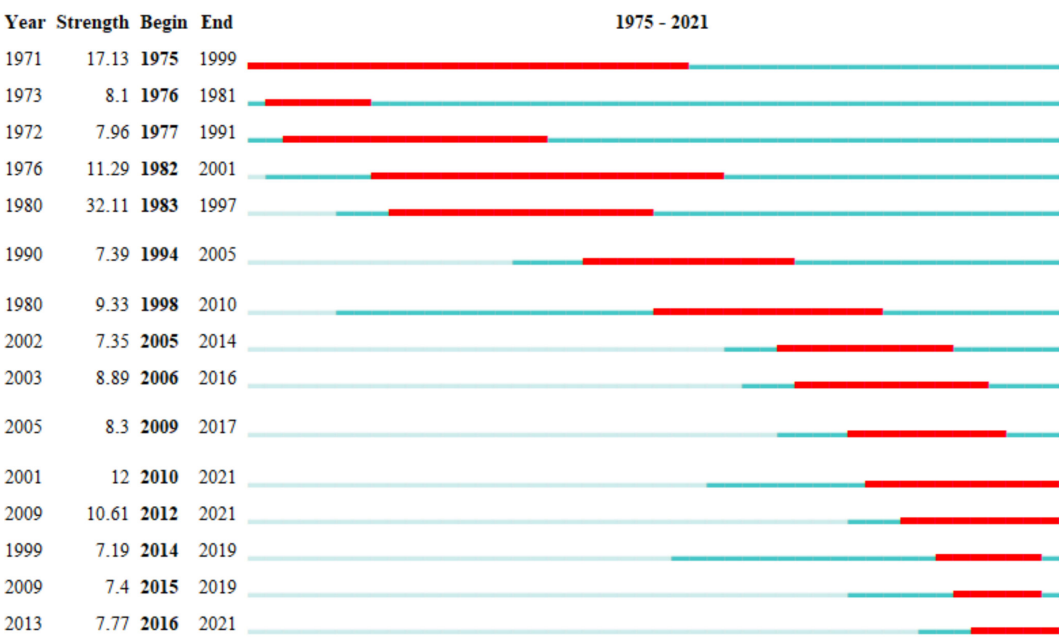

Figure 7. Top 15 references with the strongest citation bursts. Source: derived by authors from CiteSpace.

There are 63 papers with citation bursts. The book published in 1980 by Atkinson A.B. (1980) and Stiglitz J. with the title Lectures on public economics has the highest citation burst value [75]. The citation frequency of this paper started to increase in 1983 and the end was in 1997. The other top four cited references by burst are Diamond P. (1971), Saez E. (2001), Stern N.H. (1976), and Conesa J.C. (2009). Figure 7 depicts the top 15 papers with the most citation bursts, as well as the years during which they occurred. Between 1975 and 1999, the paper published by Diamond P.A. (1971) and Mirrlees J.A. attracted 
the attention of scholars. The study examined the desirability of aggregate production efficiency in a wide range of situations, assuming that taxes are set at the optimal level. The authors also examined the optimal tax structure [68]. In the past decade (2010-2020), the most frequently cited documents are the ones published by Saez E. (2001), Conesa J. C. et al.1 (2009), and Piketty T. and Saez E. (2013). Saez E. presents three reasons for using elasticities to derive optimal tax rates (1-it is straightforward to obtain an optimal tax formula for high incomes; 2 - the elasticity method shows exactly which are the relevant parameters for optimal taxation; and 3-numerical simulations can be performed using the empirical income distribution) [76]. Conesa J.C. and his colleagues found that a system that taxes capital heavily and taxes labor income according to a flat tax with a sizeable deduction is optimal in the long run [77]. Finally, in their handbook chapter, Piketty T. and Saez E. reviewed recent developments in the theory of optimal labor income taxation. They presented a conceptual background of optimal taxation; they first debated optimal linear taxation, then optimal non-linear taxation, and finally, they presented some limits and alternatives for the concepts [78].

\subsubsection{Analysis of Cited Authors}

An author co-citation network is created to identify highly cited researchers whose publications are well known by research communities. The relationship of author co-citation takes place when two scholars are cited in the same article. CiteSpace configurations were kept the same, but the sliced and merged networks were pruned using the pathfinder technique, providing 932 nodes and 5984 links with a density close to zero.

We can locate the leading researcher by looking for cited authors with a lot of citations and/or a high of betweenness centrality in Figure 8. According to Table 5, Mirrlees J.A. is the most referenced author in the field of optimal taxation with 340 citations. It demonstrates how Mirrless J.A.'s scientific endeavor served as the foundation for subsequent inquiries and as the inspiration and source of future research in optimal taxation theory all around the world [79]. The second and third most cited authors are A.B. Atkinson and P.A. Diamond, followed by Stiglitz J. E. in fourth and Lucas R.E. and Chamley C. in fifth place. Atkinson A.B. focused his research on income distribution [80] and Diamond P.A. studied optimal taxation and public production [68,81]. Stiglitz J.E. is a well-known scholar from Columbia University (U.S.A.) with thousands of publications and thousands of citations. Regarding the optimal taxation field, he analyzed the design of tax systems by identifying Pareto efficient tax structures and tried to find arguments for progressive taxation [82]. He is a co-author of Atkinson A.B.'s article about the design of tax structure [65].

Regarding betweenness centrality, there are five researchers whose betweenness centrality is higher than 0.10 , which means that they are more persuasive than other researchers and have a significant influence on the optimal taxation research expansion. These top five authors are Barro R.J. (1980), Ramsey F.P. (1975), Stiglitz J.E. (1975), Diamond P.A. (1975), and Arrow K.J. (1975). Influential or leading scholars are those who have a high citation rate as well as a high betweenness centrality. In terms of Sigma value, Barro R.J. leads, followed by Atkinson A.B., Ramsey F.P., Arrow K.J., and Feldstein M. All these authors laid, through their work, the foundation in the research of optimal taxation, and they gradually developed different aspects of the theory of fiscal optimization. 

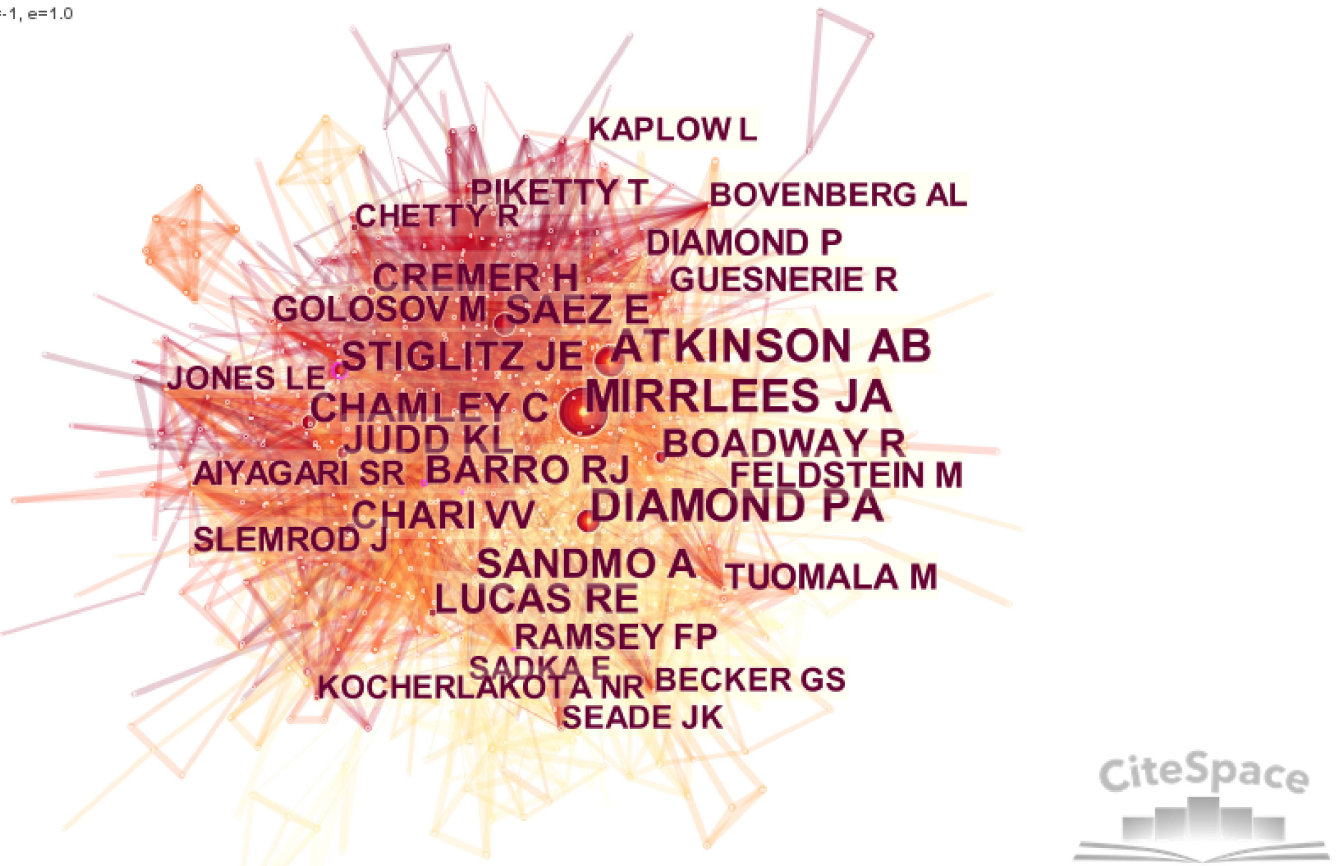

Figure 8. Visualization of author co-citation networks for optimal taxation research. Source: derived by authors from CiteSpace.

Table 5. Distribution of the top 15 cited authors in optimal taxation research.

\begin{tabular}{ccccccc}
\hline Rank & Authors & Year & Frequency & Centrality & Burst & Sigma \\
\hline 1 & Mirrlees J.A. & 1976 & 340 & 0.05 & 5.43 & 1.28 \\
\hline 2 & Atkinson A.B. & 1975 & 289 & 0.07 & 14.92 & 2.81 \\
\hline 3 & Diamond P.A. & 1975 & 256 & 0.10 & - & 1.00 \\
\hline 4 & Stiglitz J.E. & 1975 & 158 & 0.11 & - & 1.00 \\
\hline 5 & Lucas R.E. & 1983 & 135 & 0.05 & 7.70 & 1.51 \\
\hline 6 & Chamley C. & 1985 & 135 & 0.03 & - & 1.00 \\
\hline 7 & Saez E. & 2001 & 129 & 0.01 & 9.78 & 1.15 \\
\hline 8 & Sandmo A. & 1975 & 128 & 0.09 & 5.00 & 1.57 \\
\hline 9 & Judd K.L. & 1994 & 122 & 0.02 & - & 1.00 \\
\hline 10 & Boadway R. & 1981 & 118 & 0.03 & 5.17 & 1.15 \\
\hline 11 & Cremer H. & 1995 & 111 & 0.05 & - & 1.00 \\
\hline 12 & Chari W. & 1993 & 109 & 0.02 & 6.88 & 1.18 \\
\hline 13 & Barro R.J. & 1980 & 107 & 0.13 & 9.95 & 3.24 \\
\hline 14 & Ramsey F.P. & 1975 & 89 & 0.12 & 6.12 & 1.99 \\
\hline 15 & Golosov M. & 2006 & 80 & 0.01 & 7.16 & 1.09 \\
\hline
\end{tabular}

Source: derived by authors from CiteSpace.

The articles with close ties were sorted into 12 clusters after the cited authors' network was generated. Labels were developed for each cluster in CiteSpace automatically by LLR. In this network, the modularity denotes a suitable clustering structure. However, the mean silhouette value is 0.77 and can be appreciated as relatively high since there are not many small clusters. The number of the largest cluster is \#0, and the number of the smallest one is \#11. The size of a cluster is determined by the quantity of published papers within it 
and varies between 204 papers in cluster \#0 and 9 papers in cluster \#11. All of the clusters showed considerably high silhouette values, indicating high grouping quality. Cluster \#1 has the lowest silhouette of 0.72 ( close to 1.00 ( size $=11)$.

With 204 elements, the largest cluster is \#0. It is referred to as a "sticky price". The cluster's most active citer is Jacobs B. (2013). He derived a number of policy recommendations as an attempt to strictly adhere to a welfare-based optimal tax analysis [70]. Another key article included in this cluster is the one issued by Schmitt-Grohe S. and Uribe M. (2004). They studied optimal fiscal and monetary policy under sticky product prices. They showed, among other things, that tiny deviations from full pricing flexibility cause government debt and tax rates to behave in a near-random walk fashion [83].

With 135 units, the second largest cluster is \#1. "Endogenous participation" is its label. The cluster's most active citer is Boadway R. (2013). Boadway R. and Tremblay J.F. surveyed how labor market variables affect optimal income taxation and presented a catalog of unresolved issues [73]. Fleurbaey M. and Maniquet F. (2018) are the second citers from this cluster. Their work is about fairness principles and optimal income taxation theory. They investigated the contribution that concepts of fairness can have to optimal income taxation theory and sent a message: the traditional instrument of welfare economics is flexible enough to incorporate many approaches, from egalitarianism to libertarianism [84].

Furthermore, we can identify influential scholars based on citation bursts, or when a scholar is quoted a great deal in a short period of time. The citations of 103 scholars have been bursting before 2021, including Piketty T., Chetty R., Atkinson A.B., Stern N.H., and Farhi E. The top 15 cited authors with the largest citation burst are shown in Figure 9. Because of their considerable impact on optimal taxation research, these writers' papers are worth researching.

For instance, Piketty T. published in 2013 and 2014 two valuable papers that are heavily cited by researchers. The first paper was written in collaboration with Saez E. Their first study developed optimal inheritance tax formulas that take into account the important equity-efficiency trade-off. The authors looked at dynamic stochastic models with a wide range of bequest preferences and labor productivity. They showed that if the bequest elasticity is low, bequest concentration is high, and society cares most about those receiving a little inheritance, the optimal tax rate is positive and quantitatively large [85]. In the second paper, Piketty T. has Saez E. and Stantcheva S. as co-authors. Their second paper produced optimal top tax rate formulas in a model, where top earners respond to taxes through three channels: labor supply, tax avoidance, and compensation negotiating. They show that when there are zero-sum compensation-bargaining effects, the efficient top tax rate rises [86]. The formulas for optimal tax and social insurance policies derived by Chetty $\mathrm{R}$. and Saez E. highlight two general parameters as the determinants of how private insurance affects the benefits of social insurance: the size of the formal private insurance market, and the emergence of public insurance as a substitute for formal private insurance [87]. 
Cited Authors PHELPS ES

SADKA E

SHESHINSKI E

STERN NH

BARRO RJ

ATKINSON AB

JONES LE

EROSA A

KOCHERLAKOTA NR 1975

SAEZ E

CONESA JC

FARHI E

PIKETTY T

CHETTY R

JACOBS B

1975

1975

1975

1975
Year Strength Begin End

$1975-2021$

$\begin{array}{llll}1975 & 11.96 \quad 1976 & 1994\end{array}$

$\begin{array}{llll}1975 & 8.19 & 1976 & 1989\end{array}$

$\begin{array}{llll}1975 & 12.03 & 1977 & 1991\end{array}$

$1975 \quad 14.39 \quad 1980 \quad 2001$

$\begin{array}{lll}1975 & 9.95 \quad 1982 & 2004\end{array}$

$\begin{array}{llll}1975 & 14.92 & 1983 & 1998\end{array}$

$\begin{array}{llll}1975 & 9.39 & 1995 & 2005\end{array}$

$\begin{array}{llll}1975 & 7.93 & 2005 & 2014\end{array}$

$7.92 \quad 20082015$

$9.78 \quad 20112021$

$8.982012 \quad 2021$

$12.12 \quad 20142021$

15.5920162021

$15.48 \quad 2016 \quad 2021$

10.0520162021

Figure 9. Top 15 cited authors with the strongest citation bursts. Source: derived by authors from CiteSpace.

Farhi E. and Gabaix X. developed a theory of optimal taxation with behavioral agents. They revisited optimal taxation's three pillars: Ramsey, Pigou, and Mirrlees. They unified existing results in behavioral public finance to derive new insights. The authors also revisited two classical results regarding supply elasticities and production efficiency [88]. Another paper that has a citation burst in the past five years belongs to Jacobs B. and Bovenberg A.L. Their paper contributed to the literature on optimal education subsidies by demonstrating that, under a second-best optimum, education decisions are often inefficient [89].

\subsubsection{Analysis of Cited Journals}

The cited journal visualization map for optimal taxation research was obtained by applying pruning sliced networks. The network contains 1517 nodes (cited journals) and 6875 links (Figure 10). 

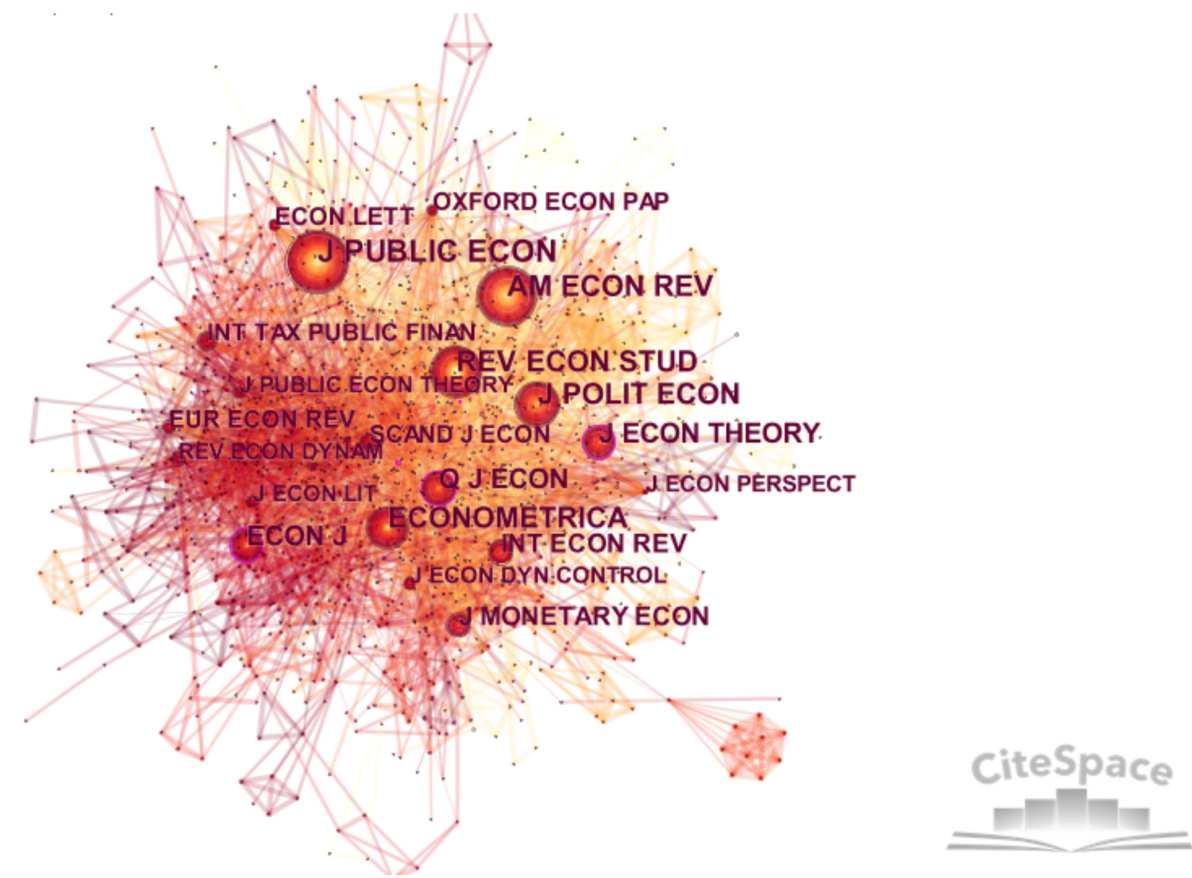

Figure 10. Visualization of journal co-citation networks for optimal taxation research. Source: derived by authors from CiteSpace.

The quantity of citations and centrality for the top 15 cited journals that published articles on optimal taxation are presented in Table 6. Journal of Public Economics is the most prominent for all citations, followed closely by American Economic Review, Review of Economic Studies, Journal of Political Economy, and Econometrica. These findings imply that a journal with a higher impact factor may have a higher frequency of citations. The Bell Journal of Economics (0.16) has the highest betweenness centrality ranking, with a score of 0.16, followed by the Canadian Journal of Economics (0.14), Economica (0.13), Journal of Economic Theory (0.11), Federal Reserve Bank (0.10), Economic Journal (0.10), Quarterly Journal of Economics (0.09) and Journal of Money, Credit, and Banking (0.09). Notably, The Bell Journal of Economics, which has the highest centrality, is not the most-cited journal. Moreover, only three cited journals from the top 10 by frequency are included in top the 10 cited journals by centrality.

The quality of cited journal clusters is expected to meet both modularity and weighted mean silhouette criteria, and this merits further investigation. The total modularity of the cited journals has a medium value, indicating that a well-structured network has not been established and that the specialties in the optimal taxation area are moderately clearly defined. The total weighted mean silhouette, which measures internal cluster homogeneity, is relatively high, indicating that clustering is highly trustworthy and that members of the related cluster are more similar than members of other clusters. There are 21 clusters for cited journals of different sizes, but with high-quality configuration. Silhouette values rank between 0.73 for cluster \#5 intergenerational disagreement and almost 1.00 for cluster \#19 learning. Moreover, if the size of the cluster decreases, then the silhouette value increases, and the cluster configuration fits the perfect solution. The largest cluster is \#0 "income splitting" and contains 147 cited journals, followed by five other clusters with over 100 cited journals. 
Table 6. Distribution of top 15 cited journals for optimal taxation research.

\begin{tabular}{|c|c|c|c|c|c|}
\hline Rank & Cited Journal & Frequency & Centrality & Burst & Sigma \\
\hline 1 & Journal of Public Economics & 691 & 0.01 & - & 1.00 \\
\hline 2 & American Economic Review & 621 & 0.02 & - & 1.00 \\
\hline 3 & Review of Economic Studies & 570 & 0.01 & 8.27 & 1.08 \\
\hline 4 & Journal of Political Economy & 478 & 0.06 & - & 1.00 \\
\hline 5 & Econometrica & 450 & 0.03 & - & 1.00 \\
\hline 6 & Quarterly Journal of Economics & 372 & 0.09 & - & 1.00 \\
\hline 7 & Journal of Economic Theory & 332 & 0.11 & - & 1.00 \\
\hline 8 & Economic Journal & 318 & 0.10 & - & 1.00 \\
\hline 9 & Journal of Monetary Economics & 237 & 0.06 & 5.79 & 1.38 \\
\hline 10 & International Economic Review & 222 & 0.06 & - & 1.00 \\
\hline 11 & The Scandinavian Journal of Economics & 173 & 0.02 & 3.89 & 1.09 \\
\hline 12 & European Economic Review & 158 & 0.08 & 4.37 & 1.38 \\
\hline 13 & International Tax and Public Finance & 150 & 0.03 & 4.99 & 1.17 \\
\hline 14 & Oxford Economic Papers & 149 & 0.07 & 7.53 & 1.62 \\
\hline 15 & Economic Letters & 149 & 0.08 & - & 1.00 \\
\hline
\end{tabular}

Source: derived by authors from CiteSpace.

With 147 components, the largest cluster is \#0. "Income splitting" is the label for it. The cluster's most active citer is Fleurbaey M. (2018) with the same paper about the contribution of fairness to optimal income taxation theory and having Maniquet F. as co-author [84]. The second-largest cluster (\#1) has 130 members. The label for it is "distance function". One of the most active citers to the cluster is Gerritsen A. (2016). The author studied the optimal nonlinear income tax and showed that it is possible to combine theoretical rigor and an emphasis on incentives with an alternative measurement of well-being. He discovered that ideal marginal tax rates should be higher for people who work too much and lower for workers who work too little [90].

Sixty cited journals have citation burst, of which the top fifteen cited journals can be found in Figure 11. As can be seen, Lectures on Public Economics is the most referenced journal with the highest citation burst, even if it is not the most cited one. It is followed by HBK Economic, American Economic Journal: Economic Policy, Working Paper, and Review of Economic Dynamics. A cited journal with a strong citation burstiness value indicates a potentially interesting journal that drew the attention of academics within a given time period. Nowadays, besides the journals presented before, researchers from the optimal taxation field are interested in journals such as Journal of the European Economic Association, Macroeconomic Dynamics, Annual Review of Economics, American Economic Journal: Macroeconomics, and Journal of Economic Behavior and Organization. 


\begin{tabular}{lrrrr}
\multicolumn{1}{c}{ Cited Journals } & \multicolumn{1}{c}{ Year Strength Begin End } \\
REV ECON STUD & 1975 & 8.27 & $\mathbf{1 9 7 5}$ & 1982 \\
ESSAYS MODERN EC & 1975 & 8.46 & $\mathbf{1 9 7 7}$ & 1990 \\
BELL J ECON & 1975 & 7.01 & $\mathbf{1 9 8 1}$ & 1996 \\
LECTURES PUBLIC EC & 1975 & 32.56 & $\mathbf{1 9 8 3}$ & 1997 \\
PUBLIC FINANC & 1975 & 7.67 & $\mathbf{1 9 9 0}$ & 2003 \\
OXFORD ECON PAP & 1975 & 7.53 & $\mathbf{1 9 9 3}$ & 2002 \\
LECT PUBLIC EC & 1975 & 9.96 & $\mathbf{1 9 9 8}$ & 2011 \\
FINANZARCHIV & 1975 & 8.76 & $\mathbf{2 0 0 3}$ & 2013 \\
DIMENSIONS TAX DESIG & 1975 & 7.06 & $\mathbf{2 0 1 1}$ & 2019 \\
AM ECON J-ECON POLIC & 1975 & 13.38 & $\mathbf{2 0 1 2}$ & 2021 \\
HBK ECON & 1975 & 15.22 & $\mathbf{2 0 1 4}$ & 2021 \\
WORKING PAPER & 1975 & 13.16 & $\mathbf{2 0 1 4}$ & 2021 \\
REV ECON DYNAM & 1975 & 12.6 & $\mathbf{2 0 1 4}$ & 2021 \\
ANNU REV ECON & 1975 & 7.46 & $\mathbf{2 0 1 6}$ & 2021 \\
\hline J ECON BEHAV ORGAN & 1975 & 7.95 & $\mathbf{2 0 1 7}$ & 2021
\end{tabular}

Figure 11. Top 15 cited journals with the strongest citation bursts. Source: derived by authors from CiteSpace.

\subsection{Keywords Co-Occurrence Analysis}

Keywords are a high-level summary of a paper's content in the form of representative words. The high frequency and centrality of co-occurrence of keywords can reflect the research field's primary topics. The analysis of similar keywords can assist in the identification of the cores of the optimal taxation research field. This part of the analysis reveals the theoretical structure of the optimal taxation field and allows us to select the main concepts and research hotspots.

Keywords are generally regarded as one of the most significant components of any research paper that seeks to identify the primary research issues in various scientific research fields [91]. The concept structure of the optimal taxation field is revealed using the co-word analysis method. In this analysis, the author's keywords and keywords created using computer techniques and bibliometrics analysis software were combined and analyzed together. To conduct a co-word analysis utilizing CiteSpace software, the configuration parameters were set up as follows: Top 50 per year (1975-2021), LRF $=-1$, LBY $=-1$, and e $=1$. The sliced networks and merged network map of co-occurrence were not pruned. Figure 12 depicts a network of co-occurring terms with 546 nodes and 3348 linkages. The frequency of keywords was used to map the co-word analysis networks. Furthermore, nodes with a frequency value greater than or equal to 20 are shown. Keywords are represented by nodes, while keyword connections are represented by links. The co-occurrence frequency of the keywords is directly correlated to the font size of the keywords. Figure 12 shows that optimal taxation is found in the center of the research. It is at the heart of research, and it has received a great deal of attention in related sectors. 


\section{growth tax policy equilibrium}

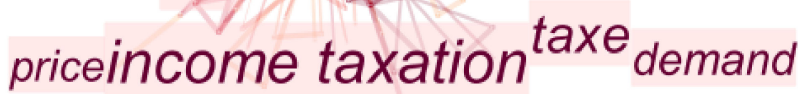

\section{monetary policyfiscal policy inequality \\ endogenous growth}

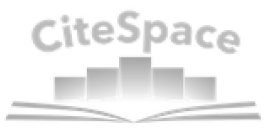

Figure 12. Keywords co-occurrence network for optimal taxation research. Source: derived by authors from CiteSpace.

The top 30 concepts with a high count are listed in Table 7. "Optimal taxation" is at the top of the list with all the keywords. "Model" is the second most used keyword, followed by "taxation". Academics are also interested in keywords such as "policy", "tax", "income taxation", "capital income", and "income". Centrality is one of the main indicators used to measure the strength, influence, or characteristics of a keyword in the analysis of the keyword co-occurrence network. Keywords with a high betweenness centrality are at the center of the network and play an essential role in connecting other keywords or research subjects. The keywords "optimal taxation" (centrality $=0.46)$, "taxation" $(0.26)$, "policy" (0.19), and "model" (0.17) show the highest betweenness centrality among all others. The betweenness centrality values of other keywords, such as "tax", "capital income", "fiscal policy", "equilibrium", and "demand", range from 0.60 to 0.80 .

Table 7. Top 30 keywords used in optimal taxation literature.

\begin{tabular}{|c|c|c|c|c|c|c|c|c|}
\hline Rank & Freq. & Keyword & Rank & Freq. & Keyword & Rank & Freq. & Keyword \\
\hline 1 & 198 & Optimal taxation & 11 & 34 & Equilibrium & 21 & 21 & Inequality \\
\hline 2 & 98 & Model & 12 & 34 & Economy & 22 & 20 & Debt \\
\hline 3 & 93 & Taxation & 13 & 33 & Fiscal policy & 23 & 20 & Externality \\
\hline 4 & 74 & Policy & 14 & 32 & Growth & 24 & 19 & Demand \\
\hline 5 & 58 & Tax & 15 & 31 & Consumption & 25 & 18 & Commodity taxation \\
\hline 6 & 53 & Income taxation & 16 & 30 & Welfare & 26 & 18 & Economics \\
\hline 7 & 45 & Capital income & 17 & 29 & Taxes & 27 & 16 & Monetary policy \\
\hline 8 & 41 & Income & 18 & 29 & Efficiency & 28 & 16 & Cost \\
\hline 9 & 36 & Optimal income taxation & 19 & 24 & Elasticity & 29 & 16 & Design \\
\hline 10 & 36 & Redistribution & 20 & 22 & Endogenous growth & 30 & 16 & Price \\
\hline
\end{tabular}

Source: derived by authors from CiteSpace.

A significant increase in the frequency of a keyword over a short period of time usually indicates research hotspots to which the scientific community pays special attention. We used keyword burst detection to find research hotspots in the field of optimal taxation. Burst keywords are typically utilized to examine the hotspots and research frontiers of 
the optimal taxation study area, as they reflect subjects that have attracted the interest of peer scientists. From the point of view of burst strength, "elasticity" (5.78) is the strongest burst, followed by "inequality" (5.68), "consumption" (5.44), "redistributive taxation" (4.11), and "taxation" (4.00). In their respective periods, they are all research hotspots. The keywords that have a burst period of more than five years are "elasticity" and "inequality" (2016-2021). These concepts received greater attention and are more influential than other keywords, indicating that they formed research hotspots in the optimal taxation field throughout the relevant years. These keywords are now research hotspots since they are still growing.

The literature was subject to a keyword clustering analysis, giving a total of ten keyword clusters in the final visualization map (Figure 13). The keyword's clustering structure was not especially relevant because it has a small value of modularity. The silhouette values of keywords clusters ranged from a minimum of 0.68 (cluster \#2) to a maximum of 0.92 (cluster \#9). The structures of clusters are reasonable (Table 8). Concerning the size of the keywords' clusters, the largest cluster (\#0) has a frequency of 86 papers, while the smallest cluster has a frequency of 16 publications. Figure 14 shows the evolution over time of optimal taxation topics used by scholars from 1975 to 2021. Apart from cluster \#9, the evolution of core research topics of optimal taxation field is constant over the years, starting in 1975 and continuing to 2020. The research topics of the most active citers in the first three clusters are summarized below.

Timespan: 1975-2021 (Slice Length $=1$ )
Selection Criteria: $\mathrm{g}$-index ( $\mathrm{k}=25$ ), LRF-1.0, L/N $=10, \mathrm{LBY}=-1, \mathrm{e}=1.0$
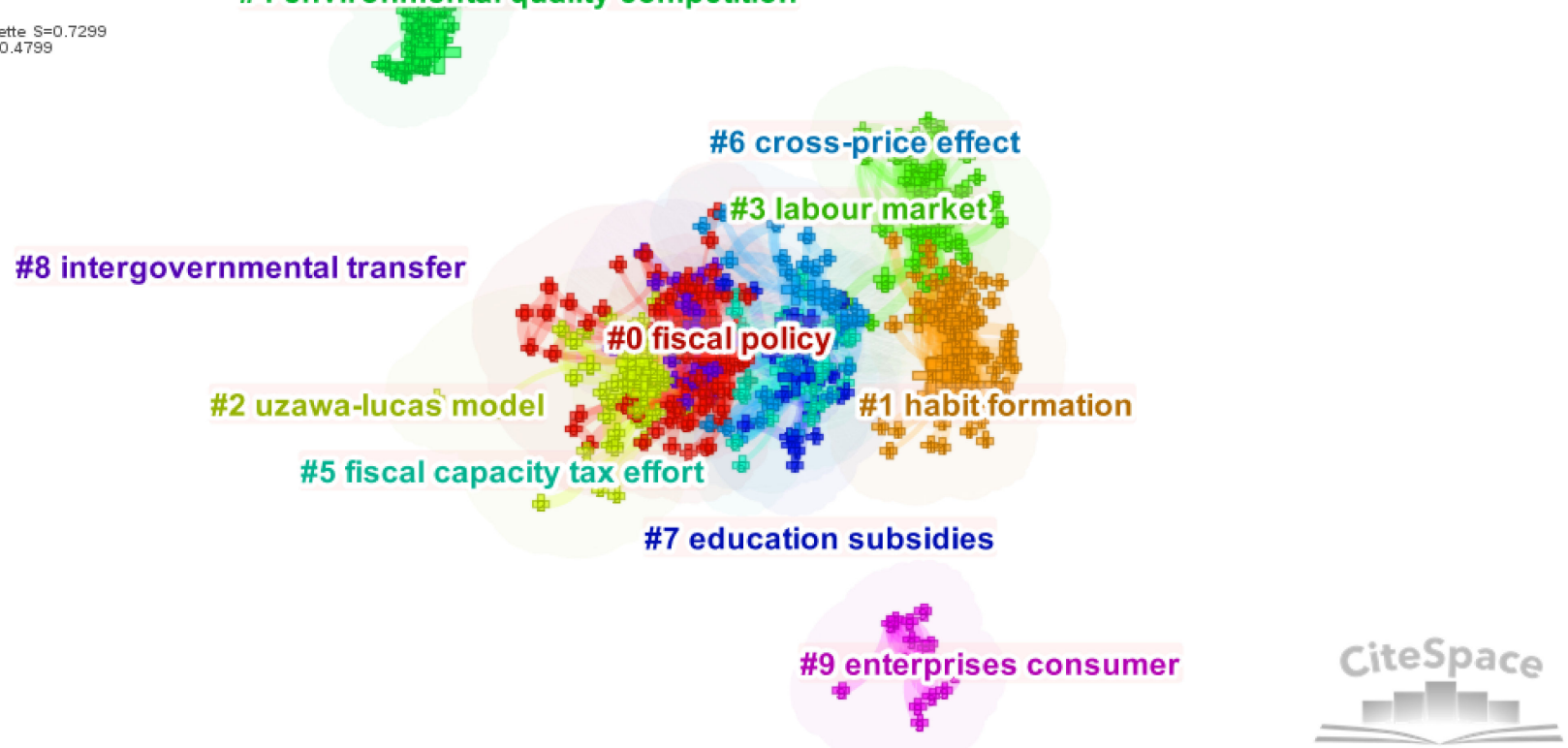

Figure 13. Clusters of the keywords co-occurrence network for optimal taxation research. Source: derived by authors from CiteSpace. 
Table 8. Clusters of keywords in optimal taxation research.

\begin{tabular}{|c|c|c|c|c|}
\hline Cluster & Size & Silhouette & Year & Keywords (by LLR) \\
\hline$\# 0$ fiscal policy & 86 & 0.72 & 2000 & $\begin{array}{c}\text { fiscal policy; monetary policy; sticky price; Friedman rule; structural } \\
\text { reform }\end{array}$ \\
\hline$\# 1$ habit formation & 78 & 0.71 & 2005 & $\begin{array}{l}\text { habit formation; social comparison; conspicuous leisure; relative } \\
\text { consumption; relative leisure matter }\end{array}$ \\
\hline \#2 Uzawa-Lucas model & 63 & 0.69 & 2004 & $\begin{array}{l}\text { Uzawa-Lucas model; capital income; productivity slowdown; } \\
\text { international investment income; equilibrium unemployment }\end{array}$ \\
\hline \#3 labor market & 58 & 0.68 & 2005 & $\begin{array}{l}\text { labor market; income tax non-compliance; recent advance; tax } \\
\text { avoidance; envy inequity aversion }\end{array}$ \\
\hline $\begin{array}{l}\text { \#4 environmental quality } \\
\text { competition }\end{array}$ & 48 & 0.72 & 2009 & $\begin{array}{l}\text { environmental quality competition; environmental tax; } \\
\text { utility-enhancing environmental quality; pollution abatement spending; } \\
\text { responsible firm }\end{array}$ \\
\hline \#5 fiscal capacity tax effort & 44 & 0.75 & 1999 & $\begin{array}{l}\text { fiscal capacity tax effort; labor market distortion; open economies; } \\
\text { non-leaky bucket; agency cost }\end{array}$ \\
\hline \#6 cross-price effect & 42 & 0.81 & 2008 & $\begin{array}{l}\text { cross-price effect; labor supply; elastic labor supply; endogenous } \\
\text { growth economy; extensive labor supply responses }\end{array}$ \\
\hline \#7 education subsidies & 34 & 0.75 & 2006 & $\begin{array}{l}\text { education subsidies; progressive taxation; general equilibrium; parents' } \\
\text { resource; children's abilities }\end{array}$ \\
\hline \#8 intergovernmental transfer & 30 & 0.76 & 2003 & $\begin{array}{l}\text { intergovernmental transfer; dynamic model; multiple level; mobile } \\
\text { capital; public spending }\end{array}$ \\
\hline \#9 enterprises consumer & 16 & 0.92 & 2015 & $\begin{array}{l}\text { enterprises consumer; environmental externalities; full internalization; } \\
\text { economic development; fiscal policy }\end{array}$ \\
\hline
\end{tabular}

Source: derived by authors from CiteSpace.

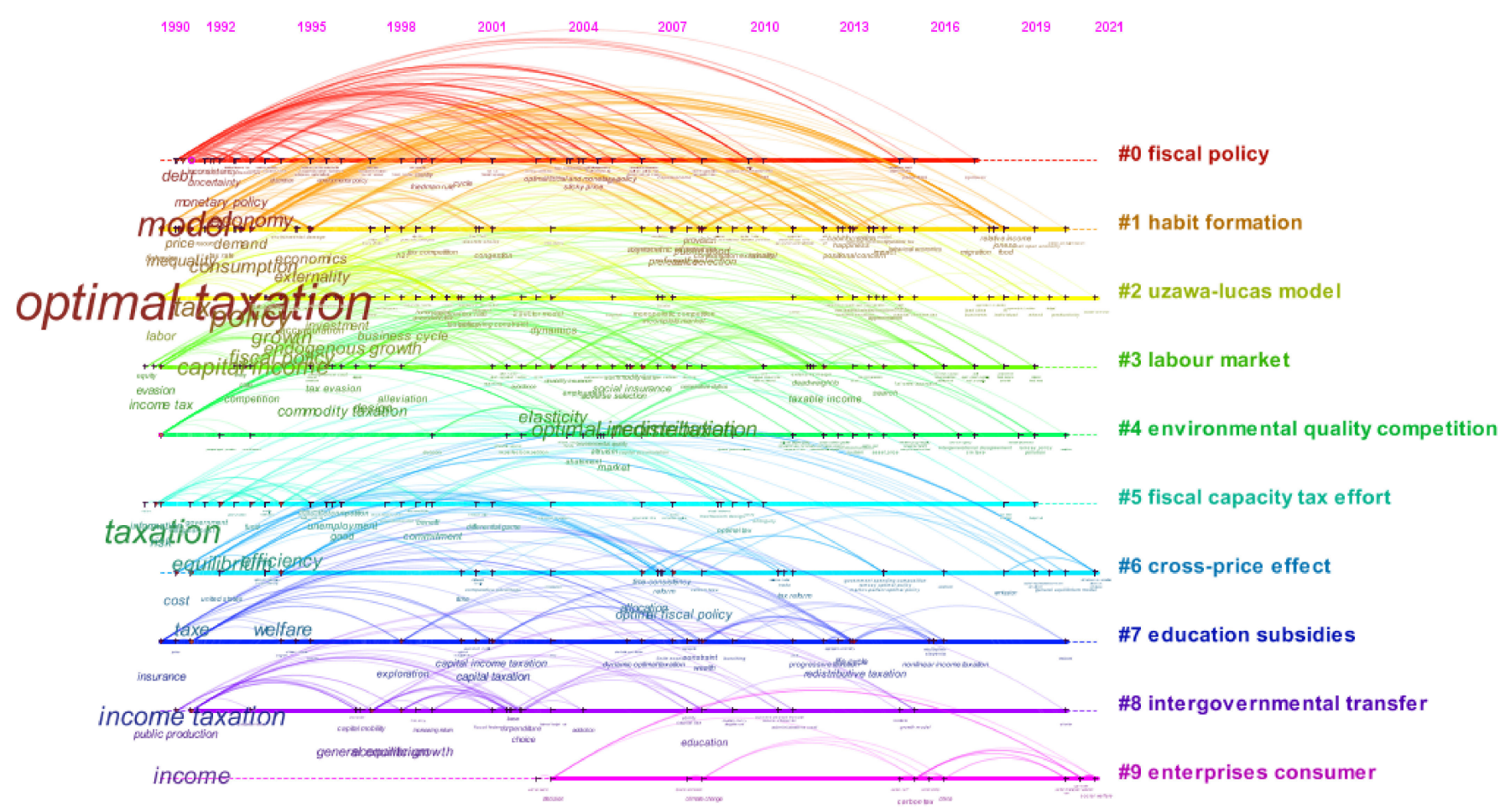

Figure 14. A timeline view of keywords co-occurrence network related to optimal taxation research. Source: derived by authors from CiteSpace.

The most populous cluster (\#0) has 86 keywords. The cluster is labeled as "fiscal policy". Cavalcanti T.T.D. (2003) is the cluster's most active citer. Cavalcanti T.T.D. and Villamil A. demonstrated that in an economy with fundamental difficulties in labor, goods, and financial markets, the Friedman rule may not be optimal. According to them, an inflation tax allows the government to eliminate the economic distortions caused by these flaws. The authors found that the optimal inflation rate is quantitatively different from the Friedman policy [92]. Cassou S. and Lansing K. (1998) are active citers in cluster \#0 
fiscal policy. They created a quantitative mathematical framework for optimal public capital allocation. Their model is being used to determine the circumstances under which a growth in the stock of public capital is preferable, as well as for studying the extent to which nonoptimal fiscal policies can be responsible for a country's productivity decline [93]. Turnovsky S. (1996) also focused on fiscal policy, and in his view, a consumption tax is an important part of an overall optimal fiscal package. He looked at the trade-off between the best income tax and the best consumption tax and showed how it is influenced by the externalities created by government spending on capital returns [94].

With 78 individuals, cluster (\#1) is the second-largest cluster. "Habit formation" is the label for it. Aronsson T. (2013) is the cluster's most active citer. Aronsson T. and Johansson-Stenman O. proposed a two-type optimal nonlinear income tax concept in which individuals are concerned with both their relative consumption and leisure. The authors demonstrated that leisure does not change the policy guideline for providing public goods [95]. Other active citers of cluster \#1 are Janda K., Lajksnerová Z., and Mikolášek, J. (2019). They provided a theoretical model for alcohol taxes and used it for empirical estimations. Their model is based on both externality adjustments and fiscal constraints, as tax increases are anticipated to have an immediate impact on other government programs, such as labor taxes and medical spending. They tested the model in Czechia [96]. The paper published by Chang J., Chen J., and Shieh J. (2012) belongs to cluster \#1. In their paper, the authors set up a dynamic model with a keeping-up-with-the-Joneses preference and market imperfections. They investigated the question presented by Ljungqvist and Uhlig and discovered that there is no evident link between the state-varying tax and the intertemporally dependent preference [97].

The alluvial diagram of optimal taxation field was created by using a web application available at https: / / www.mapequation.org/alluvial/ (accessed on 31 August 2021). We first used CiteSpace to convert the literature by the co-citation network, then uploaded the annual network information files one by one into the Alluvial Generator. We obtained the diagram shown in Figure 15 after screening the data and refining the layout.

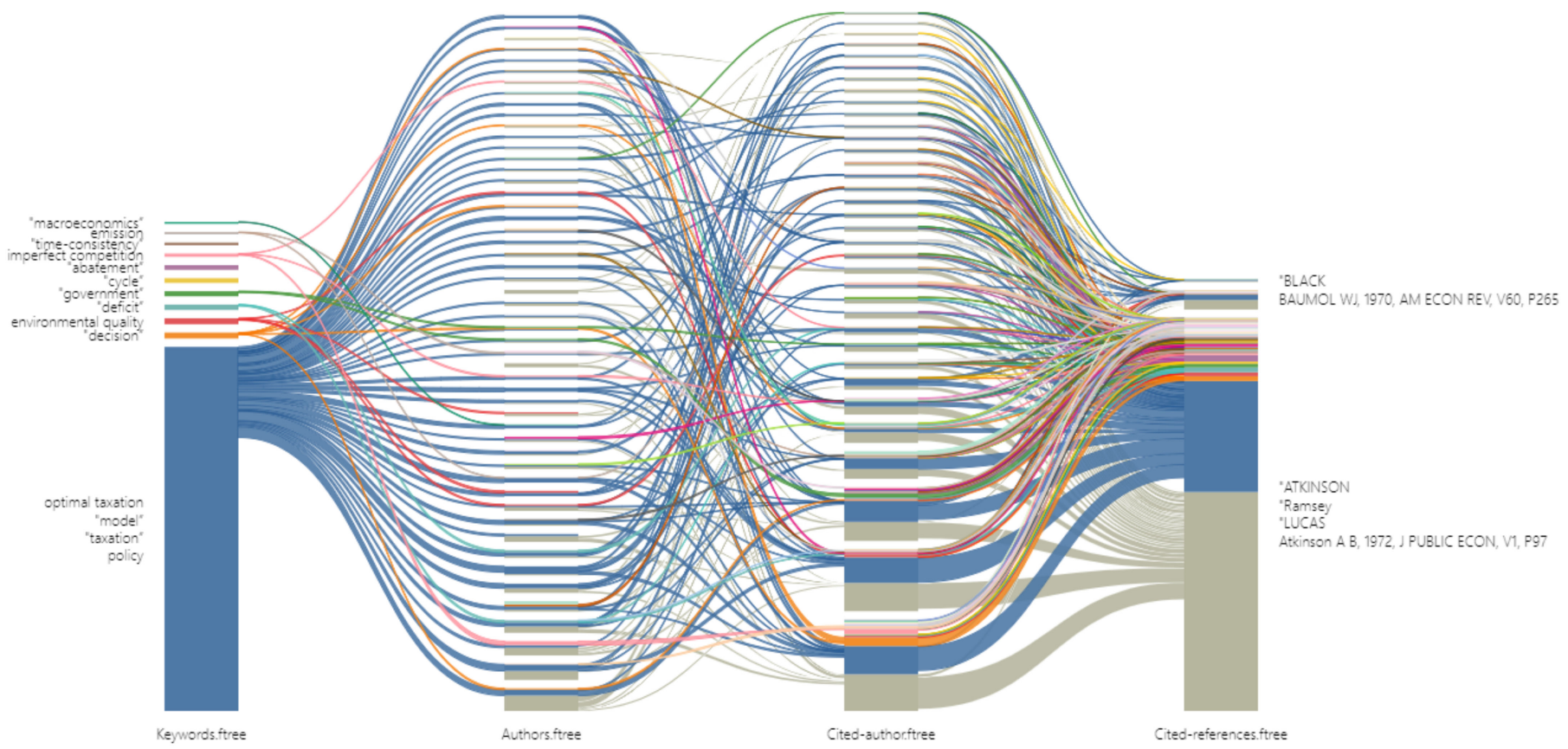

Figure 15. Alluvial diagram for optimal taxation literature. Source: created by authors using Alluvial Generator.

We used four categories of networks (keywords, authors, cited documents, and cited authors) to identify structural changes between clusters. The networks are shown as 
vertical stacks connected by streamlines. In each stack, nodes that are clustered together form a module, drawn as a rectangle. The height of the streamline is proportional to the aggregated flow in the nodes that are present in the connected modules. Module size is based on the flow, and modules are sorted by the flow. Of all the flows, $99.60 \%$ are visible. Network names and modules names are labeled. If we consider the first module, we can see that it contains 331 nodes, and the largest nodes are represented by the following keywords: "optimal taxation", "model", "taxation", "policy", "tax", and "capital". To identify the authors publishing on these topics, we have to refer to the module of authors. There are 10 nodes, and the largest nodes are represented by the following authors: Pestieau P., Marchand M., Lipszyc B., Jousten A., Boadway R., and Wibaut S. These core keywords also appear in the cited documents published by the following scholars: Ramsey F.P., Atkinson A.B., Sandmo A., Stiglitz J., and Diamond P.A. Besides them, there are almost 100 scholars in the first module searching for optimal taxation and using the cluster of keywords. The diagram in Figure 15 demonstrates the structure of topics and authors developing the knowledge in the optimal taxation field.

How fiscal policy should be determined in the long run is one of the most important topics in macroeconomics. Taxation must be optimized to maximize the well-being of society. The fiscal optimum theory can offer a series of important lessons to the public decision maker; moreover, the recent theoretical progress in this field helps to build a link between academic research and practical guidance [98]. The central objective of optimal taxation is not to maximize the national income, but to maximize the social welfare of the country because a decrease in population income is accompanied by a reduction in tax collections. Moreover, any analysis of the fiscal optimum aims to describe some taxes that the government could implement, not to explain the already existing taxes.

\section{Discussion and Conclusions}

This article starts with a brief introduction about optimal taxation and scholars with studies on this topic. Based on 1011 journal articles issued between 1975 and 2021 and indexed in WoS, a systematic overview of the optimal taxation research field is presented. As demonstrated in the tables and figures above, we identified the major authors, journals, countries, institutions, keywords, and references. Research hotspots and academic groupings in the optimum taxation field were analyzed using CiteSpace.

\subsection{Main Findings and Contribution}

The present study contributes to the existing research by delivering information on the state of the art and finding the trends, gaps, and research opportunities through the selection and content analysis of the most recent and relevant articles published in the optimal taxation research field. To summarize, the conducted literature analysis enables us to respond to the highlighted research problems. The paper illustrates the primary subject areas, leading contributors, and new scientific inquiry subjects, as well as the trends in optimal taxation research production.

In response to the first research question $R Q(1)$, we referred to the expansion of research output in the optimal taxation field as volume and distribution. The first papers published during the researched time period (1900-2021) were published in 1975. The general trend in the writing revealed a rise in the number of articles published, indicating that optimal taxation research is developing and will continue to be a hotspot. Three stages of this research field's evolution can be distinguished based on changes in the number of articles published: 1975-1986, 1987-2005, and 2006-2020. Nowadays, there is a global level of interest in the topic of optimal taxation. More scholars are recognizing the relevance of this research subject, which indicates a steady increase in publications. The U.S.A. is the leading country where article outputs focus on studying optimal taxation and tax policy. Developed countries such as the U.K., Canada, Germany, France, China, Japan, Sweden, Italy, and Australia are among the top ten countries in the world in terms of scientific contributions to optimal taxation field. The most productive authors in optimal taxation 
studies are Aronsson T., Gahvari F., Weymark J., Boadway R., and Slemrod J. Only a few researchers made significant contributions to this topic. Concerning the source journals, the most prolific journals in the optimal taxation field are Journal of Public Economics, Economic Letters, Journal of Public Economic Theory, International Tax and Public Finance, and Scandinavian Journal of Economics.

The paper's second research question RQ (2) focused on determining the collaborative patterns between leading authors, institutions, and countries contributing to outputs of optimal taxation research. Answering this question, we found that authors do not form strong relationships of collaboration. Gahvari F., Cremer H., and Craig B. were the top three collaborative authors, followed by Aronsson T., Lehmann E., Wilson J.D., Saez E., Rabindra R., Jacobs B., and Pestieu P. The main collaboration networks are not closely linked, and there are numerous disconnected cooperative networks, indicating that overall, cooperation for optimal taxation research has been lost. The analysis of the number of authors over time reveals an upward trend year after year. The number of authors interested in optimal taxation field has grown steadily from 15 persons before 1980 to over 50 persons after 2010. It must be added that the number of authors exceed the number of articles, meaning that some of them are co-authors. All these prove that the level of co-authorship increased constantly. Harvard University from the U.S.A., Academia Sinica from Taiwan, and Umea University from Sweden are the top three most impactful and collaborative institutes of the optimal taxation-related publications. Other productive institutions are Tilburg University from the Netherlands, the Catholic University of Louvain from Belgium, Massachusetts Institute of Technology from the U.S.A., and Mount Allison University from Canada. Cooperation between countries is still in its early stages and should be promoted in order to internationalize and expand research in the field. The United States occupies a critical position in creating academic exchanges and collaboration in the field of optimal taxation research.

Raising the third research question RQ (3), we identified the most widely read papers, authors, and journals in the optimal taxation research field. Based on the co-citation analysis, the significant publications in the optimal taxation field are Mirrlees J.A. (1971), Atkinson A.B. (1976), Chamley C. (1986), Judd K.L. (1985), Diamond P.A. (1971), Ramsey F.P. (1927, 0.17), and Lucas R.E. (1983). These papers are the most influential papers in the optimal taxation research field. Mirrlees J.A. is recognized as the author with the most citations, followed by Atkinson A.B., Diamond P.A., Lucas R.E., Chamley C., and Stiglitz J.E. Among other influential authors, we can find Barro R.J., Ramsey F.P., and Arrow K.J. All these authors laid, through their work, the foundation in the research of the optimal taxation and they gradually developed distinct parts of fiscal optimization theory. Journal of Public Economics is the most prominent co-cited journal, followed by American Economic Review, Review of Economic Studies, Journal of Political Economy, and Econometrica. Even if they are not the most cited journals, The Bell Journal of Economics, Canadian Journal of Economics, Economica, Journal of Economic Theory, Federal Reserve Bank, and Economic Journal are other publications that are essential in the subject of optimal taxation.

Finally, we discovered the most interesting study subjects connected to tax policy optimization by answering the fourth research question RQ (4). The most recent scientific inquiries in the discipline are focused on the following issues: "optimal taxation", "model", "taxation", "policy", "tax", "income taxation", "capital income", and "income". Elasticity, inequality, and consumption are the research hotspots of the past five years.

All the research findings bring value to the literature by providing reference ideas for the research and development of optimal taxation. The new elements introduced by our paper refer to the identification of key trends in scientific production about optimal taxation (key authors, key journals, key research teams, key articles, and research lines of optimal taxation). Our analysis is characterized by the fact that it provides a large picture of the authors, institutions, countries, keywords, journals, and research themes in the field of tax policy optimizations. In this study, bibliometric analysis was applied to provide a quantitative view on optimal taxation over the past 45 years. This investigation provides 
a content analysis of the most recent and relevant articles, exploring the areas and topics under investigation that seem to be more popular, and the directions that investigations seem to be taking. The result of our analysis constitutes a guidance for scholars interested in optimal taxation and who are looking for cooperation opportunities. This study may be useful for journals in determining their course and writers in determining which journal to submit their research to.

Through a complete mapping of the optimal taxation research field, the work adds value to research practice and tax theory. The development patterns of the optimal taxation research field are described by discovering research productivity trends and the most productive countries in tax optimization. The identification of leading contributors identifies possible collaborators (universities and academics) for further tax optimization research. Finding the most appealing source titles reveals potential for publication. Leading thematic areas and developing subjects are identified, providing directions for scholars and identifying research gaps to be investigated.

\subsection{Limitations and Future Research Directions}

Although the bibliometric analysis and visualization on optimal taxation-related papers offered some interesting results, this work has several limitations. We made every effort to execute the bibliometric analysis in the most accurate manner possible, but quantitative research, without a doubt, cannot replace qualitative research. However, computational, quantitative analysis of the literature reduces the influence of subjective judgments associated with manual, qualitative analysis of the literature. As a result, we believe that combining the two approaches will increase the levels of achievement. More research is required to learn about the various thematic clusters and research hotspots revealed in this study. A manual analysis is required, which can be accomplished using systematic review methodologies.

The fundamental problem in employing a word-based search technique is that the dataset is incomplete. Some prominent and vital papers in this topic may be excluded solely because the expression "optimal taxation" does not occur in their titles, abstracts, or keywords. Although we believe that the proper keywords were chosen to meet our goal, they may be improved in the future to allow for a more precise search of content. Another significant issue with author co-citation is that it only keeps records of the first author, so it is complicated when two authors have the same name. Errors in the datasets are not evitable.

The publications in our dataset were retrieved from the Web of Science. The use of a single database has various drawbacks. There can be influential articles in the optimal taxation scientific fields that are not covered by the WoS database. More convincing would be a multi-source search and a cross-comparison of multiple databases. Furthermore, our dataset's document type is limited to "article". Highly cited books are not listed in the findings, and writers who have contributed essential theories are not identified. Because of their languages, a huge proportion of publications cannot be processed. Papers authored in Spanish, French, Chinese, and other languages were not included in our collection since we used English search phrases. As a result, the findings of this study are unlikely to reflect the views of certain local scholars in those non-English-speaking countries.

The results obtained in the year 2021 are until the month of July, when the data collection was carried out. Future research may cover the whole year to provide a comprehensive assessment of the scientific output in 2021 and beyond. Nonetheless, the purpose of this research was to provide a comprehensive, quantitative, up-to-date evaluation of the optimal taxation scientific landscape in order to identify the most prolific authors, journals, institutions, and countries, as well as identifying the most influential research channels and research topics.

As a result, these restrictions are still issues that need to be addressed in future research. To summarize, our study does not capture every important publication on optimal taxation, 
but we feel the findings provide us with a reliable view of the knowledge area across time. This study could be repeated in the future with alternative research questions, timeframes, or other bibliometric analytic settings. For instance, a possible extension of the study could contain an analysis related to JEL codes (JEL classification system) of the publications in the sample. Future research could yield even more in-depth insights on various taxation topics. Future research may focus on studying the optimal taxation concept and related theories. Optimal taxation theoretical framework can be subject for a qualitative and manual research.

Furthermore, a content analysis or any other qualitative data interpretation can be employed in combination with this study to offer profound and novel information or insights related to optimal taxation. Researchers, practitioners, and policymakers will probably benefit from the result of this study. It allows them to gain an in-depth understanding of optimal taxation research. However, research is a continuous process, and the thematic evolution is changing over time. Future studies are therefore needed to track the changes that are taking place in the optimal taxation research themes due to the current pandemic context.

Author Contributions: Conceptualization, L.B.; methodology, L.B. and D.M.M.; software, R.-A.Ș.; validation, L.B., D.M.M. and R.-A.Ș.; formal analysis, D.M.M.; investigation, L.B.; resources, A.O.; data curation, L.B. and R.-A.S.; writing-original draft preparation, L.B.; writing-review and editing, A.O.; visualization, L.B. and R.-A.S.; supervision, A.O.; project administration, L.B.; funding acquisition, L.B. All authors have read and agreed to the published version of the manuscript.

Funding: This research was funded by Lucian Blaga University of Sibiu and Hasso Plattner Foundation research grants LBUS-IRG-2021-07.

Institutional Review Board Statement: Not applicable.

Informed Consent Statement: Not applicable.

Data Availability Statement: Data were obtained from Web of Science Core Collection and are available at https: / / www.webofscience.com/wos/woscc/summary/863b655c-f5bf-45a2-bc33-b5 088c5aed66-0007d0e5/relevance/1 (accessed on 15 July 2021).

Acknowledgments: Project financed by Lucian Blaga University of Sibiu \& Hasso Plattner Foundation research grants LBUS-IRG-2021-07.

Conflicts of Interest: The authors declare no conflict of interest. The funders had no role in the design of the study; in the collection, analyses, or interpretation of data; in the writing of the manuscript, or in the decision to publish the results.

\section{References}

1. European Commission. Taxation Trends in the European Union. In Publications Office of the European Union; European Commission: Luxembourg, 2021; p. 16. Available online: https://op.europa.eu/en/publication-detail/-/publication/d5b94e4e-d4f1-11eb-89 5a-01aa75ed71a1/language-en (accessed on 5 November 2021).

2. Lu, Y.; de Vries, W.T. A Bibliometric and Visual Analysis of Rural Development Research. Sustainability 2021, 13, 6136. [CrossRef]

3. Hong, Q.N.; Pluye, P. A Conceptual Framework for Critical Appraisal in Systematic Mixed Studies Reviews. J. Mix. Methods Res. 2019, 13, 446-460. [CrossRef]

4. Zupic, I.; Čater, T. Bibliometric Methods in Management and Organization. Organ. Res. Methods 2015, 18, 429-472. [CrossRef]

5. Chen, C.; Dubin, R.; Kim, M.C. Orphan Drugs and Rare Diseases: A Scientometric Review (2000-2014). Expert Opin. Orphan Drugs 2014, 2, 709-724. [CrossRef]

6. Chen, C.; Hu, Z.; Liu, S.; Tseng, H. Emerging Trends in Regenerative Medicine: A Scientometric Analysis in CiteSpace. Expert Opin. Biol. Ther. 2012, 12, 593-608. [CrossRef] [PubMed]

7. Branke, J.; Deb, K.; Miettinen, K.; Slowiński, R. Multi-Objective Optimization—Interactive and Evolutionary Approaches; SpringerVerlag: Berlin/Heidelberg, Germany, 2008; pp. 59-96. Available online: https://www.researchgate.net/publication/242505 658_Multiobjective_Optimization_Interactive_and_Evolutionary_Approaches_outcome_of_Dagstuhl_seminars (accessed on 5 November 2021).

8. Lieberman, E.S. Taxation Data as Indicators of State-Society Relations: Possibilities and Pitfalls in Cross-National Research. Stud. Comp. Int. Dev. 2002, 36, 89-115. [CrossRef]

9. Diamond, P.A. Taxation, Incomplete Markets and Social Security, Munich Lectures in Economics; MIT Press: Munich, Germany, $2002 ;$ p. 137. 
10. Sandmo, A. Optimal Taxation: An Introduction to the Literature. J. Public Econ. 1976, 6, 37-54. [CrossRef]

11. Lamb, M.; Lymer, A.; Freedman, J.; James, S. Taxation: An Interdisciplinary Approach to Research; Oxford University Press: Oxford, UK, 2004; pp. 1-330.

12. Pound, T.W. Tax Policy Handbook for State Legislators, 3rd ed.; The Fiscal Affairs Program, National Conference of State Legislatures: Denver, CO, USA, 2010; p. 3. Available online: http://www.ncsl.org/documents/fiscal/TaxPolicyHandbook3rdEdition.pdf (accessed on 5 November 2021).

13. Angelopoulos, K.; Economides, G.; Kammas, P. Does Cabinet Ideology Matter for the Structure of Tax Policies? Eur. J. Polit. Econ. 2012, 28, 620-635. [CrossRef]

14. Smith, A. An Inquiry into the Nature and Causes of the Wealth of Nations. Edwin, A., Ed.; Seligman: London, UK, 1901; pp. 12-15, 400-401, 436-437.

15. Ramsey, F. A Contribution to the Theory of Taxation. Econ. J. 1927, 37, 47-61. [CrossRef]

16. Mirrlees, J.A. An Exploration in the Theory of Optimum Income Taxation. Rev. Econ. Stud. 1971, 38, 175-208. [CrossRef]

17. Kanbur, R.; Paukkeri, T.; Pirttilä, J.; Tuomala, M. Optimal Taxation and Public Provision for Poverty Reduction. Int. Tax Public Financ. 2018, 25, 64-98. [CrossRef]

18. European Commission. European Semester Thematic Factsheet-Sustainability of Public Finances; European Economy, Institutional Paper; Directorate General for Economic and Financial Affairs: Brussels, Belgium, 2017; p. 1. Available online: https://ec europa.eu/info/sites/default/files/european-semester_thematic-factsheet_public-finance-sustainability_en_0.pdf (accessed on 5 November 2021).

19. Bashir, M.; Benjiang, M.A.; Komal, B.; Bashir, M.A. Analysis of Environmental Taxes Publications: A Bibliometric and Systematic Literature Review. Environ. Sci. Pollut. Res. 2021, 28, 20700-20716. [CrossRef]

20. Zhang, K.; Wang, Q.; Liang, Q.M.; Chen, H. A Bibliometric Analysis of Research on Carbon Tax from 1989 to 2014. Renew. Sustain. Energy Rev. 2016, 58, 297-310. [CrossRef]

21. Dhar, K.; Khandelwal, U. Bibliometric Analysis of Research on Goods and Service Tax from 2004 to 2019. Acad. Account. Financ. Stud. J. 2020, 24, 1-10.

22. Nevzorova, E.N.; Kireenko, A.P.; Sklyarov, R.A. Bibliometric Analysis of the Literature on Tax Evasion in Russia and Foreign Countries. J. Tax Reform 2017, 3, 115-130. [CrossRef]

23. Nevzorova, E.N.; Bobek, S.; Kireenko, A.P.; Sklyarov, R.A. Tax Evasion: The Discourse Among Government, Business and Science Community Based on Bibliometric Analysis. J. Tax Reform 2016, 2, 227-244. [CrossRef]

24. Buele, I.; Guerra, T. Bibliometric Analysis of Scientific Production on Tax Evasion in ScienceDirect, Years 2010 to 2019. J. Leg. Ethical Regul. Issues 2021, 24, 1-15.

25. Issah, O.; Rodrigues, L.L. Corporate Social Responsibility and Corporate Tax Aggressiveness: A Scientometric Analysis of the Existing Literature to Map the Future. Sustainability 2021, 13, 6225. [CrossRef]

26. Almeida, C.M.D.S.D.; Santos, C.M.V.D. Fiscal Incentives: An Analysis of the Bibliometric Viewpoint. Rev. Gest. Financ. Contab. 2019, 9, 3-17.

27. Fonseca, P.V.D.; Jucá, M.N. The Influence of Taxes on Foreign Direct Investment: Systematic Literature Review and Bibliometric Analysis. Eur. Res. Stud. J. 2020, 23, 55-77.

28. Ya'u, A.; Saad, N. Bibliometric Analysis of Published Literature on Taxation in Malaysia, based on Scopus Database. J. Bus. Manag. Account. 2021, 11, 59-86. [CrossRef]

29. Kumar, S.; Pandey, N.; Lim, W.M.; Chatterjee, A.N.; Pandey, N. What do we know about Transfer Pricing? Insights from Bibliometric Analysis. J. Bus. Res. 2021, 134, 275-287. [CrossRef]

30. Mazurenko, O.; Tiutiunyk, I. The International Tax Competitiveness: Bibliometric Analysis. Financial Markets. Inst. Risks 2021, 5, 126-138.

31. Khahro, S.H.; Farooq, S.; Ali, T.H.; Memon, N.A.; Khahro, Q.H. An assessment of research trends on FISCAL POLICY. Library Philosophy and Practice. Libr. Philos. Pract. 2020, 4817, 1-11.

32. Hood, W.W.; Wilson, C.S. The Literature of Bibliometrics, Scientometrics, and Informetrics. Scientometrics 2001, 52, $291-314$. [CrossRef]

33. Keathley-Herring, H.; Van Aken, E.; Gonzalez-Aleu, F.; Deschamps, F.; Letens, G.; Orlandini, P.C. Assessing the Maturity of a Research Area: Bibliometric Review and Proposed Framework. Scientometrics 2016, 109, 927-951. [CrossRef]

34. Herrera-Franco, G.; Montalván-Burbano, N.; Carrión-Mero, P.; Jaya-Montalvo, M.; Gurumendi-Noriega, M. Worldwide Research on Geoparks Through Bibliometric Analysis. Sustainability 2021, 13, 1175. [CrossRef]

35. Aria, M.; Cuccurullo, C. Bibliometrix: An R-Tool for Comprehensive Science Mapping Analysis. J. Informetr. 2017, 11, 959-975. [CrossRef]

36. Ulucak, R.; Sari, R.; Erdogan, S.; Alexandre Castanho, R. Bibliometric Literature Analysis of a Multi-Dimensional Sustainable Development Issue: Energy Poverty. Sustainability 2021, 13, 9780. [CrossRef]

37. Trujillo, C.M.; Long, T.M. Document Co-Citation Analysis to Enhance Transdisciplinary Research. Sci. Adv. 2018, 4, 1-9. [CrossRef]

38. Chen, C. Science Mapping: A Systematic Review of the Literature. J. Data Inf. Sci. 2017, 2, 1-40. [CrossRef]

39. Cobo, M.J.; López-Herrera, A.G.; Herrera-Viedma, E.; Herrera, F. An Approach for Detecting, Quantifying, and Visualizing the Evolution of a Research Field: A Practical Application to the Fuzzy Sets Theory Field. J. Informetr. 2011, 5, 146-166. [CrossRef]

40. Börner, K.; Chen, C.; Boyack, K.W. Visualizing Knowledge Domains. Annu. Rev. Inf. Sci. Technol. 2003, 37, 179-255. [CrossRef] 
41. Chen, C.; Ibekwe-SanJuan, F.; Hou, J. The Structure and Dynamics of Cocitation Clusters: A Multiple-Perspective Cocitation Analysis. J. Am. Soc. Inf. Sci. Technol. 2010, 61, 1386-1409. [CrossRef]

42. Darko, A.; Chan, A.P.; Adabre, M.A.; Edwards, D.J.; Hosseini, M.R.; Ameyaw, E.E. Artificial Intelligence in the AEC Industry: Scientometric Analysis and Visualization of Research Activities. Autom. Constr. 2020, 112, 103081. [CrossRef]

43. Koondhar, M.A.; Shahbaz, M.; Memon, K.A.; Ozturk, I.; Kong, R. A visualization review analysis of the last two decades for environmental Kuznets curve "EKC" based on co-citation analysis theory and pathfinder network scaling algorithms. Environ. Sci. Pollut. Res. 2021, 28, 16690-16706. [CrossRef]

44. Synnestvedt, M.B.; Chen, C.; Holmes, J.H. CiteSpace II: Visualization and knowledge discovery in bibliographic databases. AMIA Anпu. Symp. Proc. 2005, 724-728.

45. CiteSpace: Visualizing Patterns and Trends in Scientific Literature. Available online: http://cluster.ischool.drexel.edu/ \{\}cchen/ citespace/tutorial/2015/Boston.MRS.11.29.2015.pdf (accessed on 5 November 2021).

46. Chen, C.; Dubin, R.; Kim, M.C. Emerging trends and new developments in regenerative medicine: A scientometric update (2000-2014). Expert Opin. Biol. Ther. 2014, 14, 1295-1317. [CrossRef]

47. Chen, C. Searching for Intellectual Turning Points: Progressive Knowledge Domain Visualization. Proc. Natl. Acad. Sci. USA 2004, 101 (Suppl. 1), 5303-5310. [CrossRef]

48. Chen, C. CiteSpace II: Detecting and visualizing emerging trends and transient patterns in scientific literature. J. Am. Soc. Inf. Sci. Technol. 2006, 57, 359-377. [CrossRef]

49. Wang, L.; Jin, R.; Kangwa, J. Secondary Research Methods in the Built Environment, 1st ed.; Manu, E., Akotia, J., Eds.; Routledge: London, UK, 2021.

50. Chen, C. The CiteSpace Manual 2014. Available online: http://cluster.ischool.drexel.edu/ \{\}cchen/citespace/CiteSpaceManual pdf (accessed on 1 August 2021).

51. Jia, Q.; Wei, L.; Li, X. Visualizing Sustainability Research in Business and Management (1990-2019) and Emerging Topics: A Large-Scale Bibliometric Analysis. Sustainability 2019, 11, 5596. [CrossRef]

52. Jiming, X. A literature review on application progress and research prospects of CiteSpace. In Proceedings of the 2017 International Conference on Arts and Design, Education and Social Sciences (ADESS 2017), Yinchuan, China, 9-10 December 2017; Available online: http:/ / www.dpi-proceedings.com/index.php/dtssehs/article/view/17872/17378 (accessed on 5 November 2021).

53. Rosvall, M.; Bergstrom, C.T. Maps of Random Walks on Complex Networks Reveal Community Structure. Proc. Natl. Acad. Sci. USA 2008, 105, 1118-1123. [CrossRef] [PubMed]

54. Mongeon, P.; Paul-Hus, A. The journal coverage of Web of Science and Scopus: A comparative analysis. Scientometrics 2016, 106, 213-228. [CrossRef]

55. De Fonseca, B.; Sampaio, R.B.; de Araújo Fonseca, M.V.; Zicker, F. Co-authorship Network Analysis in Health Research: Method and Potential Use. Health Res. Policy Syst. 2016, 14, 34. [CrossRef] [PubMed]

56. Sonnenwald, D.H. Scientific Collaboration. Annu. Rev. Inf. Sci. Technol. 2007, 41, 643-681. [CrossRef]

57. Cremer, H.; Gahvari, F.; Ladoux, N. Externalities and Optimal Taxation. J. Public Econ. 1998, 70, 343-364. [CrossRef]

58. Cremer, H.; Gahvari, F. Uncertainty, Optimal Taxation and the Direct Versus Indirect Tax Controversy. Econ. J. 1995, 105, 1165-1179. [CrossRef]

59. Cremer, H.; Gahvari, F. Tax Evasion and Optimal Commodity Taxation. J. Public Econ. 1993, 50, 261-275. [CrossRef]

60. Kanbur, R.; Keen, M.; Tuomala, M. Optimal Non-Linear Income Taxation for The Alleviation of Income-Poverty. Eur. Econ. Rev. 1994, 38, 1613-1632. [CrossRef]

61. Kanbur, R.; Tuomala, M. Relativity, Inequality, and Optimal Nonlinear Income Taxation. Int. Econ. Rev. 2013, 54, 1199-1217. [CrossRef]

62. Pirttilä, J.; Tuomala, M. On Optimal Non-Linear Taxation and Public Good Provision in an Overlapping Generations Economy. J. Public Econ. 2001, 79, 485-501. [CrossRef]

63. Baumann, A.; Wohlrabe, K. Where have all the working papers gone? Evidence from four major economics working paper series Scientometrics 2020, 124, 2433-2441. [CrossRef]

64. Rath, K.; Wohlrabe, K. Recent trends in coauthorship in economics: Evidence from RePEc. Appl. Econ. Lett. 2016, 23, 897-902. [CrossRef]

65. Atkinson, A.B.; Stiglitz, J.E. The Design of Tax Structure: Direct versus Indirect Taxation. J. Public Econ. 1976, 6, 55-75. [CrossRef]

66. Chamley, C. Optimal Taxation of Capital Income in General Equilibrium with Infinite Lives. Econometrica 1986, 54, 607-622. [CrossRef]

67. Judd, K.L. Redistributive Taxation in a Simple Perfect Foresight Model. J. Public Econ. 1985, 28, 59-83. [CrossRef]

68. Diamond, P.; Mirrlees, J. Optimal Taxation and Public Production I: Production Efficiency. Am. Econ. Rev. 1971, $61,8-27$.

69. Lucas, R.E.; Stokey, N.L. Optimal Fiscal and Monetary Policy in an Economy Without Capital. J. Monet. Econ. 1983, 12, 55-93. [CrossRef]

70. Jacobs, B. From Optimal Tax Theory to Applied Tax Policy. Finanzarchiv 2013, 69, 338-389. [CrossRef]

71. Krueger, D.; Ludwig, A. On the Optimal Provision of Social Insurance: Progressive Taxation Versus Education Subsidies in General Equilibrium. J. Monet. Econ. 2016, 77, 72-98. [CrossRef]

72. Domeij, D. Optimal Capital Taxation and Labor Market Search. Rev. Econ. Dyn. 2005, 8, 623-650. [CrossRef] 
73. Boadway, R.; Tremblay, J.F. Optimal Income Taxation and the Labor Market: An Overview. CESifo Econ. Stud. 2013, 59, 93-148. [CrossRef]

74. Findeisen, S.; Sachs, D. Education and Optimal Dynamic Taxation: The Role of Income-Contingent Student Loans. J. Public Econ. 2016, 138, 1-21. [CrossRef]

75. Atkinson, A.B.; Stiglitz, J. Lectures on Public Economics; McGraw-Hill Book Co.: London, UK; New York, NY, USA, 1980.

76. Saez, E. Using Elasticities to Derive Optimal Income Tax Rates. Rev. Econ. Stud. 2001, 68, 205-229. [CrossRef]

77. Conesa, J.C.; Kitao, S.; Krueger, D. Taxing Capital? Not a Bad Idea after All! Am. Econ. Rev. 2009, 99, 25-48. [CrossRef]

78. Piketty, T.; Saez, E. Chapter 7-Optimal Labor Income Taxation. In Handbook of Public Economics; Elsevier: Amsterdam, The Netherlands, 2013; Volume 5, pp. 391-474.

79. Mirrlees, J.A. Optimal Tax Theory: A synthesis. J. Public Econ. 1976, 6, 327-358. [CrossRef]

80. Atkinson, A.B. Distribution of Income and Wealth-Agenda. New Soc. 1975, 32, 472-474.

81. Diamond, P.A.; Mirrlees, J.A. Optimal Taxation and Public Production II: Tax Rules. Am. Econ. Rev. 1971, 61, $261-278$.

82. Stiglitz, J.E. Chapter 15-Pareto Efficient and Optimal Taxation and The New Welfare Economics. In Handbook of Public Economics; Elsevier: Amsterdam, The Netherlands, 1987; Volume 2, pp. 991-1042.

83. Schmitt-Grohé, S.; Uribe, M. Optimal Fiscal and Monetary Policy Under Sticky Prices. J. Econ. Theory 2004, 114, 198-230. [CrossRef]

84. Fleurbaey, M.; Maniquet, F. Optimal Income Taxation Theory and Principles of Fairness. J. Econ. Lit. 2018, 56, 1029-1079. [CrossRef]

85. Piketty, T.; Saez, E. A Theory of Optimal Inheritance Taxation. Econometrica 2013, 81, 1851-1886.

86. Piketty, T.; Saez, E.; Stantcheva, S. Optimal Taxation of Top Labor Incomes: A Tale of Three Elasticities. Am. Econ. J. Econ. Policy 2014, 6, 230-271. [CrossRef]

87. Chetty, R.; Saez, E. Optimal Taxation and Social Insurance with Endogenous Private Insurance. Am. Econ. J. Econ. Policy 2010, 2, 85-114. [CrossRef]

88. Farhi, E.; Gabaix, X. Optimal Taxation with Behavioral Agents. NBER Work. Pap. 2015, 110, 21524.

89. Jacobs, B.; Bovenberg, A.L. Optimal Taxation of Human Capital and The Earnings Function. J. Public Econ. Theory 2011, 13, 957-971. [CrossRef]

90. Gerritsen, A. Optimal taxation when people do not maximize well-being. J. Public Econ. 2016, 144, 122-139. [CrossRef]

91. Gao, F.; Jia, X.; Zhao, Z.; Chen, C.C.; Xu, F.; Geng, Z.; Song, X. Bibliometric Analysis on Tendency and Topics of Artificial Intelligence over Last Decade. Microsyst. Technol. 2019, 27, 1545-1557. [CrossRef]

92. De, V.; Cavalcanti, T.; Villamil, A. Optimal Inflation Tax and Structural Reform. Macroecon. Dyn. 2003, 7, $333-362$.

93. Cassou, S.P.; Lansing, K.J. Optimal Fiscal Policy, Public Capital, and The Productivity Slowdown. J. Econ. Dyn. Control. 1998, 22, 911-935. [CrossRef]

94. Turnovsky, S.J. Optimal Tax, Debt, and Expenditure Policies in a Growing Economy. J. Public Econ. 1996, 60, 21-44. [CrossRef]

95. Aronsson, T.; Johansson-Stenman, O. Conspicuous Leisure: Optimal Income Taxation When Both Relative Consumption and Relative Leisure Matter. Scand. J. Econ. 2013, 115, 155-175. [CrossRef]

96. Janda, K.; Lajksnerová, Z.; Mikolášek, J. A General Equilibrium Model of Optimal Alcohol Taxation in the Czech Republic. Prague Econ. Pap. 2019, 28, 589-611. [CrossRef]

97. Chang, J.-J.; Chen, J.-H.; Shieh, J.-Y. Consumption Externalities, Market Imperfections and Optimal Taxation. Int. J. Econ. Theory 2012, 8, 345-359. [CrossRef]

98. Honohan, P. Taxation of Financial Intermediation: Theory and Practice for Emerging Economies; World Bank; Oxford University Press: Washington, DC, USA, 2003; p. 33. Available online: https://openknowledge.worldbank.org/handle/10986/15122 (accessed on 5 November 2021). 